
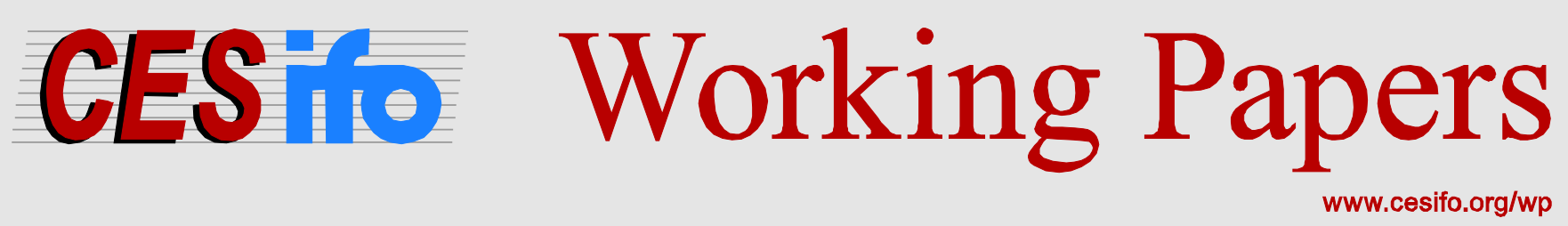

\title{
Explaining Inequality Between Countries: The Declining Role of Political Institutions
}

\author{
Andrew J. Hussey \\ Michael Jetter \\ Dianne McWilliam
}

\begin{abstract}
CESIFO WORKING PAPER NO. 6320
CATEgory 6: Fiscal Policy, MaCROECONOMICS AND GROWTH JANUARY 2017
\end{abstract}

An electronic version of the paper may be downloaded

- from the SSRN website:

- from the RePEc website:

- from the CESifo website:

WwW.SSRN.com

www.RePEc.org

www.CESifo-group.org/wp 


\title{
Explaining Inequality Between Countries: The Declining Role of Political Institutions
}

\begin{abstract}
Within the fundamental determinants of cross-country income inequality, 'humanly devised' political institutions represent a hallmark factor that societies can influence, as opposed to, for example, geography. Focusing on the portion of inequality explainable by differences in political institutions, we decompose annual cross-country Gini coefficients for 95 countries (representing 85 percent of the world population) from 1960-2012. Since 1988, inequality has marginally decreased (from a Gini of 0.525 to 0.521 ) but the portion that cannot be explained by political institutions has increased substantially (from 0.411 to 0.459 ). Specifically, the explanatory power of institutions fell rapidly from the late 1980s to the early 1990s. This result prevails when using alternative variables, expanding the sample, weighting countries by population size, and controlling for the remaining fundamental determinants of income: culture and education. Over the same timeframe, the explanatory power of geographical conditions has been rising. This phenomenon appears to be global and is unlikely to be driven by contemporary regional events alone, such as the fall of the Soviet Union, Asian success stories (e.g., China), or institutional monocropping in Africa. A corollary of our finding implies that, if we hold societies responsible for their political institutions, inequality has become notably less fair since the late 1980s.
\end{abstract}

JEL-Codes: D630, D720, E020, O110, O430, O470.

Keywords: fairness of income inequality, fundamental determinants of development, international inequality, political institutions.

\author{
Andrew J. Hussey \\ University of Memphis \\ 423 Fogelman Admin. Bldg. \\ USA - Memphis, TN 38152-3120 \\ ajhussey@memphis.edu
}

\author{
Michael Jetter \\ University of Western Australia \\ 35 Stirling Highway \\ Australia - Crawley 6009, WA \\ mjetter7@gmail.com
}

\author{
Dianne McWilliam \\ University of Western Australia \\ 35 Stirling Highway \\ Australia - Crawley 6009, WA \\ dianne@mcwilli.am
}




\section{Introduction}

In a long line of research, Douglass North and, more recently, Daron Acemoglu, Simon Johnson, and James Robinson (AJR from hereon) have established the role of political institutions in defining countries' income levels and, accordingly, inequality across countries. ${ }^{1}$ Consequently, societies are, at least to some degree, responsible for their country's economic performance via the formation of political institutions, which in turn determine economic institutions. In particular, political institutions are commonly defined as 'humanly devised' (North, 1990) and 'man-made factors' that are 'ultimately the choice of society' (Acemoglu and Robinson, 2012). These definitions starkly contrasts at least one other fundamental determinant of income levels: geography, which commonly refers to agricultural suitability, climate, disease exposure, natural resource abundance, ruggedness, or simply the geographical location with respect to other countries (e.g., landlocked or island status). ${ }^{2}$

A key difference between explaining international income inequality with political institutions, as opposed to geography, lies in the degree of human responsibility. Indeed, this is likely the main conclusion of the associated hypothesis advocated by AJR - that countries are not destined to be poor because of due to bad luck (e.g., geography) but, rather, choices related to their institutions matter. ${ }^{3}$ Put differently, if political institutions are the driving factor of international inequality, then societies can, at least to some degree, be held responsible for developments in international income inequality. Conversely, if geography was the key determinant, less could be done to alleviate income inequality across countries.

\footnotetext{
${ }^{1}$ See North and Thomas (1973), as well as North $(1990,1994)$. For the more recent work by Acemoglu, Johnson, and Robinson, we refer to Acemoglu et al. (2001, 2002, 2005), Acemoglu (2008), and Acemoglu and Robinson (2012). We also point to Rodrik et al. (2004) in this context.

${ }^{2}$ Among others, Jeffrey Sachs and several co-authors have argued for the importance of these geographical conditions (e.g., Sachs and Warner, 1997, Gallup et al., 1999, Sachs, 2001, Sachs and Malaney, 2002, and Sachs, 2003). Nunn and Puga (2012) examine the role of ruggedness.

${ }^{3}$ Of course, a number of exogenous factors may influence choices related to political institutions, such as particular historical events (e.g., colonization or the slave trade) and domestic distribution of de facto and de jure political power. However, we will not focus on these underlying dynamics.
} 
The following pages offer a new look at cross-country income inequality and its development over time by decomposing a cross-country Gini index into the explanatory power of political institutions and geography. We employ a recently developed method for decomposing a standard Gini index into 'responsibility factors' and 'non-responsibility factors' (see Almås et al., 2011, 2012). A strict application of this responsibility concept then labels any income inequality that is explainable by political institutions as 'fair inequality,' i.e., explained by a responsibility factor. In turn, any remaining income inequality will be labeled as 'unfair inequality,' i.e., stemming from non-responsibility factors. In extensions and robustness checks, we also consider culture and education as two remaining fundamental determinants of economic development. (We consider both cases of defining these variables as responsibility and non-responsibility factors to ensure our results are not driven by that grouping.)

We focus on political institutions for two reasons. First, a large body of literature finds that institutions not only explain and determine income levels, but likely matter more than other fundamental long-term determinants, such as culture or geography (Knack and Keefer, 1995; Acemoglu et al., 2001, 2005; Rodrik et al., 2004; Acemoglu and Robinson, 2012). Second, from a policy perspective, it is important to know how much of international inequality can be attributed to human activity and decisions, as opposed to exogenous factors that humanity cannot influence. If we seek to alleviate inequality between countries we are likely most interested in those determinants that society might be able to shape. In this context, geography is virtually impossible to change and it has been found that culture tends to persist over long time periods. ${ }^{4}$ Conversely, history shows that political institutions can be changed relatively quickly. For example, rapid institutional reforms were undertaken across many developing countries in the early 1990s (Savoia and Sen, 2016) and Rodrik et al. (2004) attest that 'institutions have changed remarkably in the last three decades.' Considering the explanatory power of political institutions for

\footnotetext{
${ }^{4}$ An interesting question would also be whether and how much influence is exerted by culture (e.g., see Nunn and Wantchekon, 2011, Voigtländer and Voth, 2012, or Alesina et al., 2013, among others for how cultural attitudes may change over time). However, the present paper focuses on the importance of political institutions in describing international inequality.
} 
inequality, our analysis focuses on whether and how this relationship has changed since the 1960s. A priori, it is not obvious whether and how political institutions may explain inequality differently at different points of time.

Our analysis uses country-year level data for GDP per capita and the quality of political institutions. Considering a large sample of 95 countries (equivalent to approximately 85 percent of the world population), we derive an adjusted Gini coefficient for each year, where income differences explainable by political institutions are excluded and rather used to calculate the reference point of no inequality. Thus, the adjusted Gini compares the actual cross-country distribution of income to what the distribution of income would look like if it were based solely on the quality of countries' political institutions. Interpreted literally, and if we assume that political institutions are the responsibility of societies, the adjusted Gini then represents unfair inequality, i.e., inequality that is not explainable by political institutions.

Our key finding shows that political institutions have been explaining less and less of international inequality since the late 1980s, with a substantial drop occurring between 1988 and 1993. Today, differences in political institutions are only half as powerful for explaining inequality as in the 1970s and 1980s. At the same time, geographical variables have become stronger predictors of international income inequality, approximately doubling their magnitude. From a normative perspective, if institutions were the only fundamental determinant that we hold countries accountable for, inequality between countries has become more unfair over the last 20 years, i.e., less explainable by institutions as a responsibility factor. This trend remains robust when $(i)$ considering a larger sample of countries (over a shorter period of time), (ii) testing alternative measures for geography, institutional quality, and per capita income, and (iii) weighting countries by their population size. Further, this finding holds when controlling for cultural attributes and education levels - the two other fundamental determinants of countries' income levels.

We then consider whether particular historical events are able to account for the declining explanatory power of institutions. In particular, we focus on Eastern Europe 
after the fall of the Soviet Union, the rise of China and other Asian success stories, as well as institutional monocropping in Africa, following Evans (2004). ${ }^{5}$ However, none of these region-specific contemporary events are able to explain this phenomenon, hinting at a general, global development.

The paper proceeds as follows. Section 2 provides a background on international income inequality, discussing the relevant literature. Section 3 describes the data, while Section 4 explains the adjusted Gini technique. In Section 5, we present the main empirical findings. Section 6 examines whether particular historical events are responsible. Finally, Section 7 concludes.

\section{Background}

We focus on inequality between countries, commonly referred to as 'international inequality', which accounts for approximately 85 percent of global inequality, as opposed to within-country inequality (Milanovic, 2005, 2012a). ${ }^{6}$ The best predictor of a child's future income is the country they are born in, and, according to Milanovic (2012a), even the poorest citizens of Denmark will be far richer than the richest in Mali. International inequality is typically considered in terms of two concepts: unweighted and populationweighted inequality (Milanovic, 2005). Due to rapid growth in highly populated nations, such as China and India, the evolution of population-weighted inequality has been different to that when all countries count equally (Bourguignon et al., 2004; Sala-i-Martin, 2006; Milanovic, 2013). We concentrate on unweighted international inequality, but considering population-weighted inequality does not affect our results (see Section 5.2). We refer the reader to Section A.3.1 in the appendix for further discussion of the associated

\footnotetext{
${ }^{5}$ Institutional monocropping refers to the imposition of 'best practice' Western-style institutional reforms on the global South, which occurred mainly during the 1980s and 1990s (Mkandawire, 2012; Savoia and Sen, 2016).

${ }^{6}$ The significance of international inequality (i.e., inequality between countries) is further highlighted by the United Nations including the need to 'reduce inequality among countries' as part of their global Sustainable Development Goals (UN General Assembly, 2015).
} 
literature on concepts of world inequality.

Examining unweighted inequality over the post-war period, Milanovic (2012b) finds that while inequality (measured by Gini coefficients) remained relatively stable over the 1960s and 1970s, countries rapidly diverged over the 1980s and 1990s. ${ }^{7}$ He attributes this increased inequality to the poor performance of the former Soviet Union, the 'lost decade' in Latin America, and substantial declines in many African nations. However, he shows that alongside improved growth in these regions, unweighted inequality reached a turning point in 2001. ${ }^{8}$ Since 2001, average growth rates for large parts of Sub-Saharan Africa and other developing countries have been consistently higher than those of the developed world. While the spread of income between countries has become more equal, unweighted international inequality is still considerably higher today than in the 1960s and 1970s.

In explaining differences in income levels across countries, the literature typically distinguishes between two distinct groups: fundamental and proximate. This paper considers fundamental determinants, that is, the 'deeper' factors that drive differences between rich and poor countries (Rodrik et al., 2004; Acemoglu et al., 2005). These stand in contrast to proximate causes of economic growth, such as factor accumulation and technological change (Hall and Jones, 1999; Hsieh and Klenow, 2010). For example, Acemoglu (2008) proposes that the incentives for 'accumulation, investment, and trade' (as more proximate factors) are ultimately shaped by fundamental determinants, in particular, institutions. ${ }^{9}$

Following influential work by North and Thomas (1973) and North (1990), an extensive body of literature has established institutions as a major, and perhaps the most important, fundamental determinant of income levels (Knack and Keefer, 1995; Hall and Jones, 1999; Acemoglu et al., 2001, 2002; Rodrik et al., 2004; Acemoglu et al., 2005; Tan, 2010; Acemoglu and Robinson, 2012). We focus specifically on the role of political in-

\footnotetext{
${ }^{7}$ In seminal studies of convergence between countries, Pritchett (1997) finds a general trend of 'divergence, big time' dating back to 1870 and Sala-i-Martin (1996) notes considerable sigma divergence over the period of 1960 to 1990.

${ }^{8}$ The exact timing of this turn has been disputed, with Bourguignon et al. (2004) suggesting that inequality rose until at least 2002 and Anand and Segal (2014) finding divergence until at least 2005.

${ }^{9}$ Acemoglu (2008) offers further detail regarding the distinction between fundamental and proximate determinants.
} 
stitutions. This aligns with Acemoglu et al.'s (2005) 'hierarchy of institutions', whereby political institutions influence economic institutions, which in turn determine economic outcomes and, accordingly, international income inequality.

The conclusion that 'institutions matter most' is not unanimous, with some evidence pointing toward the importance of other fundamental determinants. Therefore, after focusing on institutions and geography at first, we eventually also consider culture and education (e.g., see Guiso et al., 2006, or Gorodnichenko and Roland, 2011, for culture; we refer to Glaeser et al., 2004, and Lee and Kim, 2009, for the role of education). Section A.3.2 in the appendix provides more detail on the associated literature concerning the fundamental determinants of income levels. To be clear, we do not seek to enter the debate over which determinant matters the most for income levels, but rather how determinants explain international income inequality and how this relationship may have changed over time. In fact, the validity of institutions as a causal determinant of growth is not necessarily inconsistent with a theory that emphasizes other factors (Brock and Durlauf, 2001; Durlauf et al., 2005).

Of the studies that assess the determinants of international inequality, most focus on explaining the trend in population-weighted inequality and mainly consider the role of certain countries, especially China (Firebaugh and Goesling, 2004; Chotikapanich et al., 2012; Ram, 2015). To our best knowledge, no research has attempted to directly assess how any of the fundamental determinants of income levels might explain the trend in either unweighted or population-weighted inequality. ${ }^{10}$ Perhaps the closest studies to ours are those that consider institutions when assessing convergence between countries. In this context, we build on work by Keefer and Knack (1997), who propose that "the ability of poor countries to catch up is determined in large part by the institutional environment in which economic activity in these countries takes place." More recently, Tan (2010) similarly concludes that institutions generally 'rule' overall when explaining

\footnotetext{
${ }^{10} \mathrm{~A}$ separate body of literature explores the relationship between institutional quality and withincountry inequality (Chong and Gradstein, 2007; Glaeser, 2008; Savoia et al., 2010), although this should not be confused with this paper, which focuses on the relationship between national institutions and inequality between countries.
} 
cross-country divergence. However, these works tend not to consider how institutions may have become more or less important for explaining inequality at different points in time.

Knack (1996) hints at this idea. At first glance, his findings imply the need for institutional reform in poorer nations to facilitate convergence to the rich. However, he then contends that

'it does not necessarily follow that [the] sudden adoption [of good institutions] by other nations, in the absence of other [e.g., cultural] changes, would show similar results: perhaps those nations, which would benefit from reform have already reformed, and those which would benefit less have not reformed.'

This encapsulates the notion that the relationship between the quality of institutions and international inequality might change. We build on Knack's (1996) argument by examining whether and how the explanatory power of political institutions has, in fact, changed over time.

\section{Data}

\subsection{The Baseline Sample}

Given the availability of information on political institutions and comparable GDP per capita numbers (which we will discuss shortly), we initially consider a baseline sample of 95 countries, representing approximately 85 percent of the world population (see appendix Table A.1 for a list). Covering the period from 1960 to 2012, this balanced sample generates 5,035 country-year observations. In additional estimations, we will show that our results are robust to extending the sample to an even larger number of countries, at the expense of a shorter time frame. The baseline sample includes countries from Africa (24), Asia (22), Eastern Europe (6), Latin America (21) and Western Europe, North America, and (rich) Oceania (WENAO) (22). These include 18 of the 20 largest countries by population size. Bangladesh and Vietnam are the two exclusions due to incomplete 
institutional quality data dating back to 1960, although our results are robust to including them later as part of the larger, yet shorter sample. In the baseline case, we begin in 1960 as this represents the earliest year that PPP-adjusted income data are widely available for most former colonies (Milanovic, 2005) and GDP per capita estimates are generally considered far more reliable for this post-war period (Lindgren, 2008).

Our analysis includes key measures of per capita incomes and the quality of political institutions. For the baseline results, we control for a set of geographical variables, including latitude (in line with Hall and Jones, 1999, and Mirestean and Tsangarides, 2016), as well as binary variables for whether a country is an island or landlocked, following Gallup et al. (1999) and Acemoglu et al. (2001). For robustness tests, we draw variables from conventional country-level data sources and provide further detail of these when relevant. Appendix Table A.2 gives descriptions of all variables used in the empirical analysis.

\subsection{Per Capita Incomes}

To measure income inequality, we assess differences between countries' GDP per capita in terms of Purchasing Power Parity (PPP). It is now accepted best practice that PPP, rather than market exchange rates, be used to convert GDP per capita to comparable measures of standards of living (Milanovic, 2012b; Anand and Segal, 2014; Piketty et al., 2014; Lakner and Milanovic, 2016). ${ }^{11}$ We draw baseline data from Gapminder (2014), which provides updated figures for the most recent (2011) round of the International Comparison Program (ICP) PPP estimates. ${ }^{12}$ In acknowledging debate surrounding the reliability of the 2011 PPP figures (Deaton and Aten, 2014; Inklaar et al., 2014; Ravallion, 2014) and of the ICP more generally (Piketty et al., 2014), we confirm results using an alternative

\footnotetext{
${ }^{11}$ For example, Anand and Segal (2008) note that using market exchange rates underestimates the real standard of living in poorer countries and therefore tends to overstate inequality. See Dowrick and Akmal (2005) or Ortiz and Cummins (2011) for an overview of the biases inherent in both market exchange rate and PPP-adjusted comparisons.

${ }^{12}$ Gapminder (2014) data, available under http://www.gapminder.org/data/, are compiled from several sources. For example, Maddison online is the major source for national growth rates. Gapminder provides complete documentation of how the data are compiled and standardized on its website (Lindgren, 2011a; Lindgren, 2011b; Johansson and Lindgren, 2014).
} 
set of per capita income data drawn from the Penn World Table (Heston et al., 2012). These employ the 2005 ICP PPP estimates and so help to alleviate concerns regarding the sensitivity of inequality estimates to different PPP rates (Milanovic, 2012b).

Figure 1 plots the standard Gini coefficients for the baseline sample, which measure inequality in GDP per capita and are expressed as 3-year moving averages. It is apparent that unweighted international inequality has mostly increased over time, with the standard Gini rising from 0.491 in 1960 to a peak of 0.553 in 2001. The most rapid divergence can be seen from the mid 1980s until the early 2000s. To add perspective, in 1960, the richest country in the sample, Switzerland, had a per capita income that was 48 times that of the poorest country, Ethiopia. By comparison, at the peak of disparity in 2001, the richest country, now Luxembourg, was 170 times richer than the poorest country, the Democratic Republic of Congo. Importantly, however, inequality between countries reached a turning point in 2001. In total, inequality rose by 12.6 percent up until 2001 but has since declined by 5.8 percent, returning to a degree similar to that seen in the late $1980 \mathrm{~s}$.

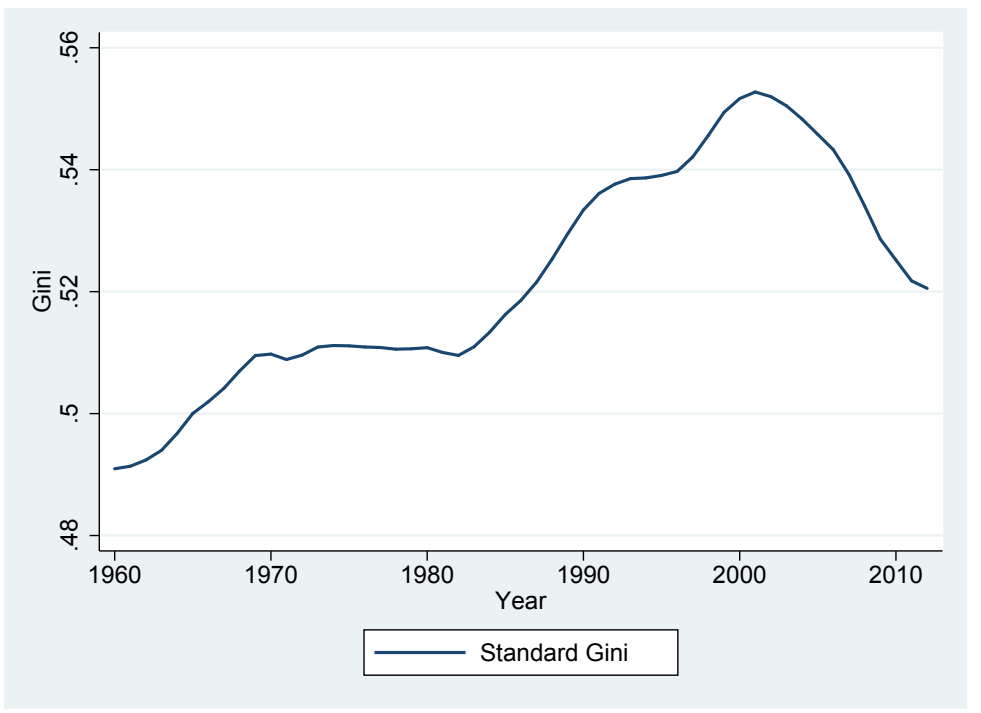

Figure 1: Standard Gini coefficients for inequality in GDP per capita, using the benchmark sample of 95 countries from 1960 to 2012.

This trend in inequality is consistent with Milanovic (2012b), who similarly observes a 'reversal of divergence' after 2001. Here, the Ginis are of a different magnitude to those of 
Milanovic (2012b), although this is to be expected given that estimates vary depending on the number of countries in the sample and the source and form of income data (Milanovic, 2005). Later robustness checks confirm that our results are unlikely to be driven by any of these aspects. Furthermore, these baseline Ginis are generally within close range to other inter-country Ginis estimated in the associated literature (Firebaugh, 1999; Anand and Segal, 2014).

\subsection{Political Institutions}

For an indicator of the quality of political institutions, we first refer to Keefer and Knack (1997), Acemoglu and Johnson (2005), and Acemoglu (2008), who highlight the importance of checks on the executive, i.e., having institutions that inhibit governments from undertaking dramatic or overly frequent policy changes that benefit themselves ahead of society. Accordingly, an ideal measure of institutional quality would be the index of executive constraints provided by the Polity IV dataset (established by Marshall and Jaggers, 2002), as this directly captures the 'extent of institutionalized constraints on the decision-making powers of chief executives' (Marshall et al., 2014).

However, the limited availability of executive constraints considerably restricts the sample to 52 (rather than 95) countries over 1960 - 2012. Therefore, as a baseline measure we instead favor the polity 2 variable, drawn from the Polity IV dataset, which has been widely used in the empirical literature as a combined indicator of institutional quality (Huang, 2010; Hodler and Raschky, 2014; Mirestean and Tsangarides, 2016). Measuring the degree of democracy of each country, polity 2 ranges from -10 to +10 (the larger the score, the greater the institutional quality) and is built from three component variables, one of which, importantly, is the index of executive constraints. Note that polity2 has fewer missing observations than executive constraints due to different treatment of instances of 'central authority interruption, collapse, or transition'. ${ }^{13}$

\footnotetext{
${ }^{13}$ polity 2 is a modification of the annual polity score; formed to facilitate the use of polity in time-series analyses (Marshall et al., 2014). In forming polity2, the authors (Marshall and Jaggers, 2002) apply a 'fix' to polity that 'converts instances of standardized authority codes (i.e., $-66,-77$, and -88) to conventional
} 
In fact, Gleditsch and Ward (1997) propose executive constraints as the most important component variable underlying polity2. Assessing the period from 1980 onwards, where executive constraints becomes available for a larger sample of 92 countries, polity 2 and executive constraints display a correlation of 0.961 , which highlights their high comparability. Nonetheless, we later confirm the robustness of results when using executive constraints for the years following 1980. Finally, employing polity 2 generally allows for a larger sample of countries over a substantially longer time period than can be achieved using alternative indicators of institutional quality, such as risk of expropriation or other measures drawn from the International Country Risk Guide (as used in Keefer and Knack, 1997, Hall and Jones, 1999, and Acemoglu et al., 2001).

Figure 2 visualizes average polity 2 scores for the baseline sample, indicating that the average quality of political institutions across all countries has been rising (left graph), with a particularly rapid increase over the late 1980s and early 1990s. Assessing the trend by region (right graph) shows that much of this rise is due to striking advances in institutional quality in both Eastern Europe and Africa over this period.
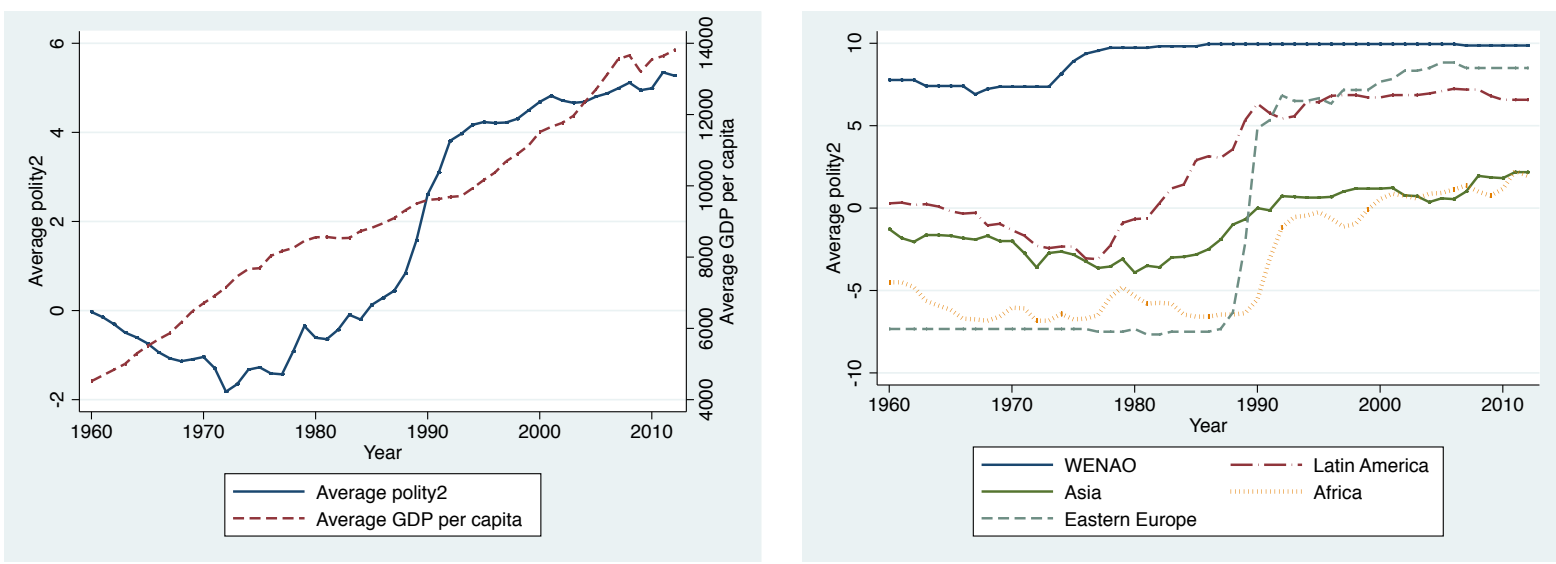

Figure 2: Left: Average GDP per capita and institutional quality (polity2) for all 95 countries from 1960 to 2012. Right: Average institutional quality (polity2) by region for all 95 countries from 1960 to 2012.

Of course, examining average trends in institutional quality cannot offer much insight polity scores' (i.e., ranging between -10 and +10 ), which explains the greater availability of polity 2 in contrast to executive constraints. 
regarding income inequality and so this is precisely where decomposing the standard Gini finds its worth. With these descriptive statistics in mind, we now turn to discussing our methodological approach.

\section{Methodology}

\subsection{Adjusted Ginis: Background}

The standard Gini coefficient measures inequality by comparing the actual distribution of income between agents (in this case, countries) to a reference distribution where total income is shared evenly. However, inequality does not necessarily need to be measured with reference to this egalitarian distribution of income. Instead, Almås et al. (2011) propose a generalized framework for measuring inequality that is calculated in reference to a new, adjusted income distribution. Under this new reference point for 'perfect equality' (i.e., a Gini of zero), countries do not necessarily have equal incomes. Rather, countries' 'adjusted incomes' account for differences in any variables that are included in their set of what Almås et al. (2011) label responsibility factors. Further, Almås et al. (2011) refer to the new reference distribution as the 'fair income distribution' because any inequality that is explainable by responsibility factors will not be captured in this adjusted Gini index. The egalitarian distribution underlying the standard Gini represents only one special adjusted income distribution under this generalized framework. ${ }^{14}$

In our main estimation, we consider polity 2 as a responsibility factor, whereas other factors, most notably geography, remain as non-responsibility factors. ${ }^{15}$ This means that any income differences stemming from institutional differences will not be captured in the adjusted Gini but rather provide a reference point for perfect equality. In turn,

\footnotetext{
${ }^{14}$ For further detail on the generalized framework, including justification that it satisfies the four standard conditions for inequality measures (anonymity, scale invariance, generalized Pigou-Dalton, and unfairism), see Almås et al. (2011) and Almås et al. (2012).

${ }^{15}$ Intuitively, in this case if all countries had the same quality political institutions, and therefore the same adjusted incomes, the adjusted Gini would equal the standard Gini.
} 
any income differences we cannot explain (or only explain via geography) will form part of the adjusted Gini. Throughout the paper, we will indicate alternative groupings of responsibility and non-responsibility factors as we consider alternative estimations, e.g., when incorporating cultural factors and education.

A strict interpretation of the adjusted Gini would then label the adjusted Gini as the 'unfair' inequality that remains after 'fair' inequality (i.e., inequality explainable by political institutions) has been taken into account (see Almås et al., 2011). ${ }^{16}$ This interpretation assumes agents have some level of control over any income determinants included in the set of 'responsibility factors' (in our case political institutions), but are unable to influence 'non-responsibility factors' (here geography), i.e., their 'circumstances'. The shape of the adjusted income distribution then depends on whichever determinants are included in the responsibility set.

Introducing this methodology, Almås et al. (2011) assess inequality between individuals in Norway, for example considering hours worked and years of education as responsibility factors, while age and gender constitute non-responsibility factors. Accordingly, they derive an income distribution that is adjusted only for hours worked and years of education. The inequality that exists beyond this adjusted reference distribution can be seen as unfair, since it is due to factors outside the responsibility of individuals, i.e., their age and gender. While Almås et al. (2011) find that the standard Gini had decreased over the period, unfair inequality had actually increased.

Finally, note that when there is only one determinant within the responsibility set, the difference between the adjusted Gini and standard Gini gives the portion of inequality which can be explained by that determinant. We refer to this difference as the contribution of the determinant to inequality or its explanatory power.

\footnotetext{
${ }^{16}$ Beyond Almås et al. (2011), the adjusted Gini technique has been used in several other studies of unfair inequality within countries, including Brazil (Figueiredo and Junior, 2014), France (Carpantier and Sapata, 2013), South American nations (Aristizábal-Ramírez et al., 2015), and the United States (Hussey and Jetter, 2016).
} 


\subsection{Adjusted Ginis: Derivation}

The first step in deriving the adjusted income distribution is a standard ordinary least squares regression, estimating per capita income, $y_{i t}$, of country $i$ in year $t$. Variables representing the fundamental determinants of income levels are grouped into either the responsibility set, $x_{i t}^{R}$, or the non-responsibility set, $x_{i t}^{N R}$. This regression takes the basic form of

$$
\log \left(y_{i t}\right)=\beta x_{i t}^{R}+\gamma x_{i t}^{N R}+\varepsilon_{i t},{ }^{17}
$$

where $\varepsilon_{i t}$ represents the standard error term. Then, to determine the share of world income that each country is allocated under the adjusted income distribution, we adopt a so-called generalized version of the classical proportionality principle (Bossert, 1995; Konow, 1996), in line with Almås et al. (2011). This stipulates that a country's adjusted income will reflect what the average income would be if all other countries shared the same responsibility factors as that country (Almås et al., 2011). Using the results of regression (1) in conjunction with this generalized proportionality principle (GPP), we follow Almås et al. (2011) to define a country's adjusted income, $z_{i t}^{G P P}$, as

$$
z_{i t}^{G P P}=\frac{\exp \left(\beta x_{i t}^{R}\right)}{\sum_{j} \exp \left(\beta x_{j t}^{R}\right)} \sum_{j} y_{j t},
$$

where $i \neq j$.

For the baseline results, we consider a world where inequality between countries depends on two fundamental determinants: quality of political institutions, as well as geography. In particular, we include polity 2 into the responsibility set, $x_{i t}^{R}$ and leave the geographical variables in $x_{i t}^{N R}$. Further, any unobserved or omitted variables (as captured by the error term) are also initially assumed to be non-responsibility factors (Almås et al., 2011). However, we eventually relax this assumption by including proxies for culture and

\footnotetext{
${ }^{17}$ In practice, this regression is built into the adgini command developed by Almås et al. (2012) to compute both standard and adjusted Ginis using Stata. Equation 1 corresponds to equation (6) in Almås et al. (2011). The default distribution of the adgini command is log linear (Almås et al., 2012).
} 
education.

Like the standard Gini, the adjusted Gini is then derived via construction of a Lorenz curve, although this should be thought of as an adjusted Lorenz curve. Instead of ranking countries by their cumulative actual incomes as in the case of the standard Lorenz curve, the adjusted Lorenz curve ranks countries by the difference between their actual and adjusted incomes (Almås et al., 2011). Accordingly, for a sample of $n$ countries, the adjusted Gini, $G^{U}$, (termed the unfairness Gini in Almås et al., 2011) is derived following the equations:

$$
\begin{gathered}
G^{U}=\frac{1}{2 n(n-1) \mu} \sum_{i} \sum_{j}\left|u_{i t}-u_{j t}\right|{ }^{18} \\
u_{i t}=y_{i t}-z_{i t}^{G P P}
\end{gathered}
$$

and

$$
\mu=\frac{\sum_{i} y_{i}}{n}
$$

Note that if for all $i, z_{i t}^{G P P}=\mu$, equation 3 is equivalent to the equation for the standard Gini. Thus, if at least one country's adjusted income, $z_{i t}^{G P P}$, differs from the average world income, $\mu$, the adjusted Gini differs from the standard Gini. When the reference distribution is adjusted only to reflect differences in polity 2 scores, the adjusted Gini represents the portion of inequality that cannot be accounted for by institutional quality. ${ }^{19}$ For all sets of results we derive standard and adjusted Ginis, expressing both as 3-year moving averages in order to smooth trends and remove possible effects of business cycles and measurement error. For example, the Ginis attributed to 2000 are calculated by averaging the estimates for 1999, 2000, and 2001 (in a similar way to Solt, 2016). As a final step, we calculate the absolute contribution of political institutions to inequality

\footnotetext{
${ }^{18}$ Almås et al. (2011) provide a simplified version of this equation: $G^{U}=\frac{2}{n(n-1) \mu} \sum_{i} i u_{i}$.

${ }^{19}$ It should be noted that, while the standard Gini lies on a scale from zero to one, the adjusted Gini can theoretically range between zero and two (Almås et al., 2011). Nonetheless, while the adjusted Gini point estimates are not entirely accurate 'portions' in technical terms, meaningful insights come from comparing the relative size of the adjusted and standard Ginis over time.
} 
by subtracting the adjusted Gini from the standard Gini in each year. ${ }^{20}$

\section{$5 \quad$ Empirical findings}

\subsection{Baseline Results}

Panel $A$ in Figure 3 graphs the standard and adjusted Ginis over time, derived from the baseline sample and expressed as 3-year moving averages. The adjusted Gini assumes polity 2 to be a responsibility factor, whereas geographical factors (latitude, landlocked, and island) form part of the non-responsibility factors. Table 1 presents the full list of all adjusted Ginis, along with measures of their absolute and relative contributions.

Panel $A$ : Gini coefficients

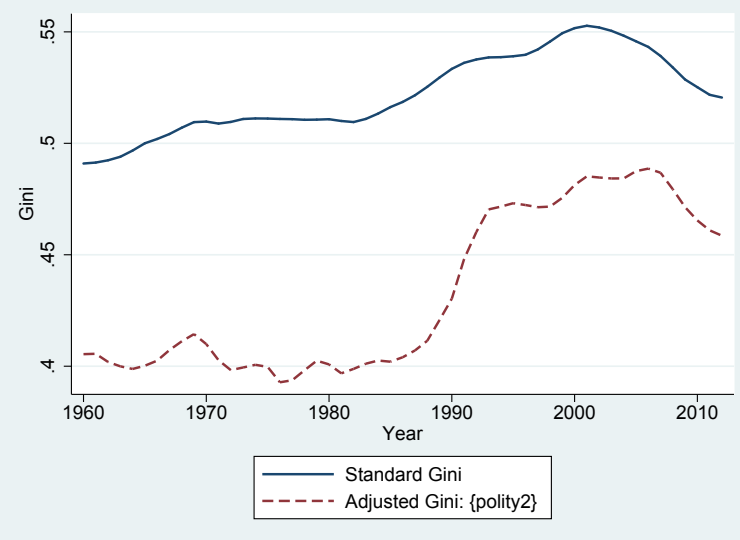

Panel B: Explanatory power

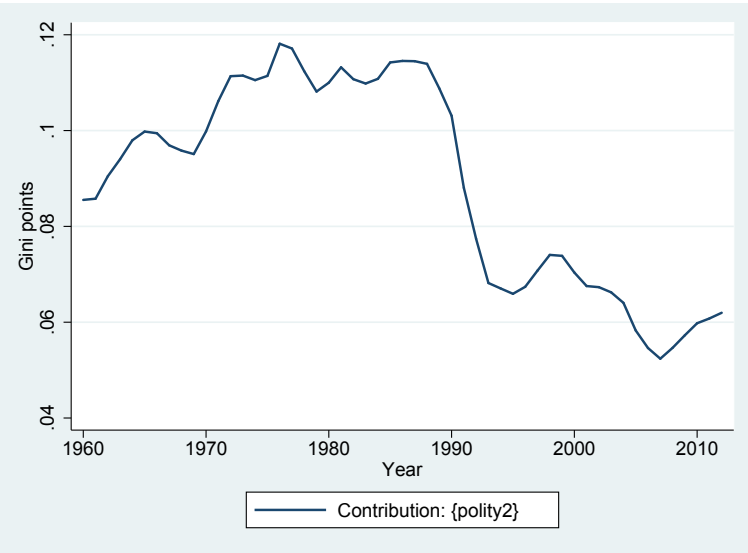

Figure 3: Annual Ginis for all 95 countries from 1960 to 2012, where $x_{i t}^{R}=\{$ polity2 $\}$ and $x_{i t}^{N R}=\{$ geography $\}$.

Panel $A$ reveals that, generally, the two Gini measures have moved in line with each other over the majority of years. However, there is one notable exception: from 1988 to 1993, the adjusted Gini rapidly increased, shrinking the gap to the standard Gini. Today, the standard Gini is only 6 percent higher than in 1960 (0.491 to 0.521), whereas the Gini adjusted for institutional differences has increased by twice as much (13 percent, 0.405 to

\footnotetext{
${ }^{20}$ This can also be expressed as a relative contribution, that is, as a percentage of the standard Gini. In practice the trends in both absolute contributions and relative contributions are almost identical, so for simplicity we consider absolute contributions as the key indicator of the explanatory power of institutions.
} 


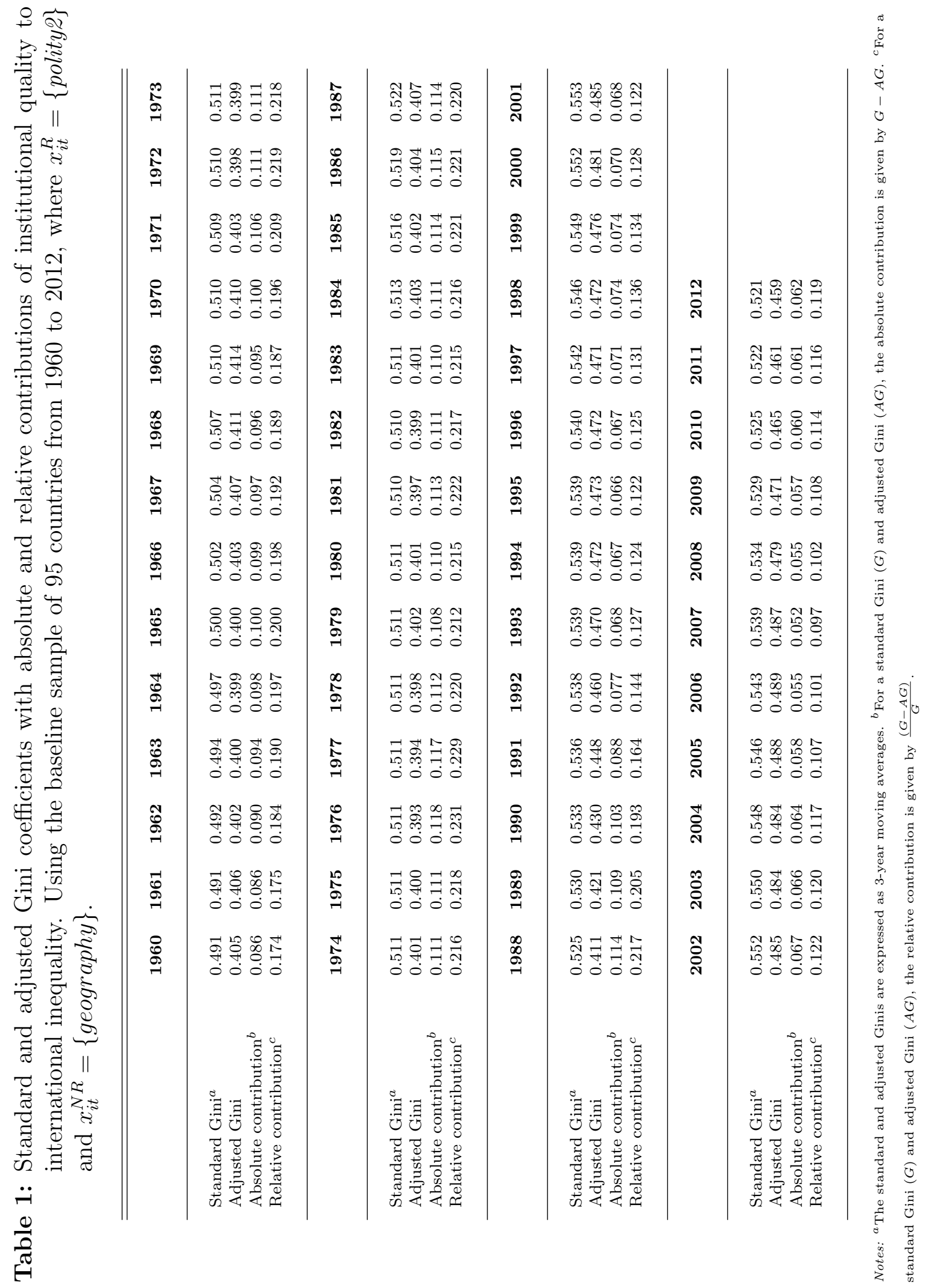


0.459). Thus, the portion of inequality that cannot be explained by institutional quality is now substantially larger than it was over the 1960 s to 1980 s, with this change occurring in the late 1980s and early 1990s.

If we view political institutions as the only fundamental determinant for which countries should be held responsible, the upward trend in the adjusted Gini implies that inequality has become more unfair over the last two decades. This key finding is shown in a more intuitive way in panel $B$, which plots the absolute contribution of institutions to inequality, reflecting the gap between the standard and adjusted Ginis. It becomes clear that the explanatory power of political institutions has noticeably decreased over the last two decades.

Table 1 documents that considering the relative contribution of political institutions produces an almost identical trend to the absolute contributions. Using this measure, by 1993, institutional quality could explain 40 percent less of inequality than compared with just five years earlier (0.114 to 0.068). Notably, Milanovic (2005) also focuses on the period from 1988 to 1993, finding a substantial increase in global inequality (i.e., between all individuals in the world) over these years. He partly attributes this to rising inequality between countries, in line with economic crises affecting a large number of transition economies. Considering the timing of this rapid drop - coinciding with the end of the Cold War - one might expect changes in Eastern European countries to be driving this downward trend. However, we show in Section 6 that this does not appear to be the case.

Following this rapid drop, the explanatory power of institutional quality does not recover but instead continues to fall, for the most part, over the last couple of decades. Although the average quality of institutions has been improving over the last two decades (Figure 2), these results suggest that the decreasing inequality seen since 2001 cannot be explained well by differences in countries' political institutions. In fact, today the explanatory power of institutions is near the lowest it has been over the last fifty years.

A natural question that emerges with this assessment is then whether geography, the other fundamental determinant of income levels considered here, has become more im- 
portant to compensate for the declining role of political institutions. Figure 4 visualizes results from considering a hypothetical scenario in which geography is moved into the responsibility set, while polity 2 remains in the non-responsibility set. Thus, any inequalities stemming from our geographical variables (latitude, landlocked, and island) are used to determine the comparison point of zero inequality, whereas inequality explainable by political institutions remains part of this particular adjusted Gini.

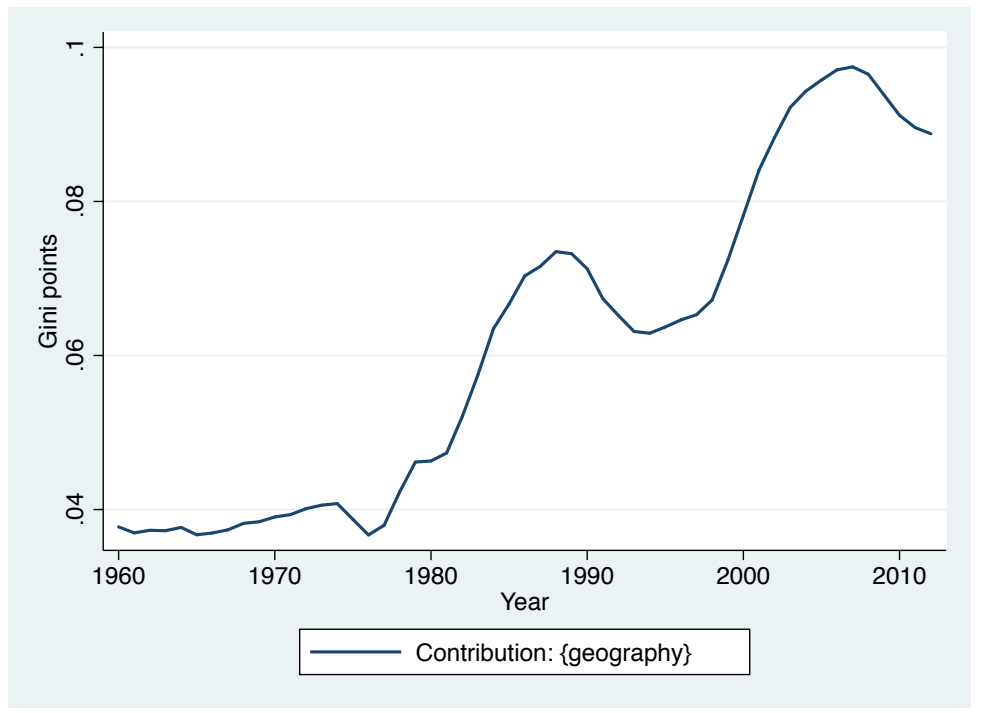

Figure 4: Contribution of geography when considering the baseline sample of 95 countries from 1960 to 2012, where $x_{i t}^{R}=\{$ geography $\}$ and $x_{i t}^{N R}=\{$ polity 2$\}$.

Figure 4 reveals that, coinciding with the declining explanatory power of institutions, geography has become better in predicting international inequality. In fact, geography today is able to explain approximately twice as much of international inequality as in the early 1980s. Translated to a fair-unfair dimension, this suggests that international inequality has become less fair over that time, i.e., more of international inequality can be explained by factors outside human control.

\subsection{Robustness Checks}

Overall, the late 1980s appear to mark a crucial turning point in the extent to which political institutions can account for the distribution of income between countries. However, 
129 countries (93\% of world pop); 1980 - 2012150 countries (96\% of world pop); $1991-2012$
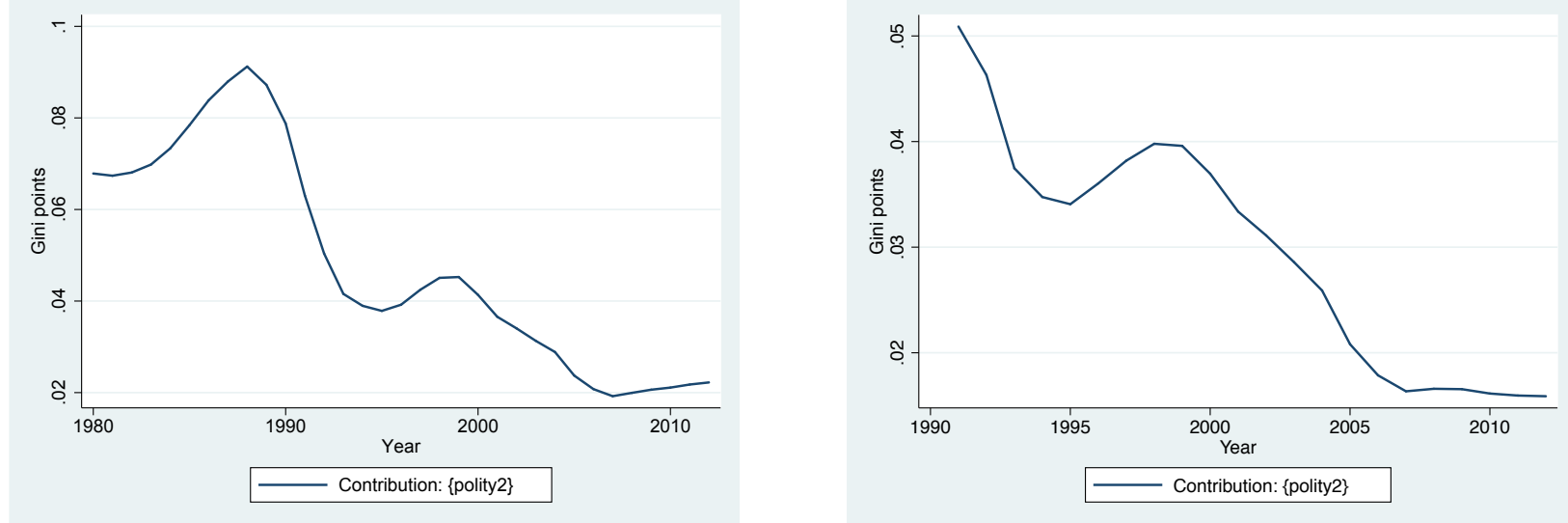

Figure 5: Explanatory power of institutional quality (polity2) for international inequality, where $x_{i t}^{R}=\{$ polity2 $\}$ and $x_{i t}^{N R}=\{$ geography $\}$.

our primary sample only includes those countries for which data is consistently available dating back to 1960. Today, these countries tend to have marginally higher average levels of GDP per capita and polity2 scores than is found in a cross-section of all countries. Therefore, to ensure that this baseline sample is not driving the results we consider a shorter time period, from 1980 onwards. This allows for the inclusion of a larger sample of 129 countries, now capturing those for which data was missing for at least one year between 1960 and 1980. This sample represents 93 percent of the world population and includes the 20 most populous countries. As shown in Figure 5 (left graph), the key downward trend in the explanatory power of institutions is not unique to the baseline sample. Furthermore, with an even larger sample of 150 countries from 1991 (right graph), where data become widely available across Africa, Asia, and Eastern Europe in particular, the main trend continues to hold.

In addition to altering the sample of countries, we test for robustness to a number of alternative measures for geography, institutional quality, and per capita incomes, with the results shown in Figure 6. First, using the index of executive constraints as an alternative indicator of institutional quality allows for a sample of 92 countries (79 percent of the world population) over 1980 to 2012. Shown in Panel $A$, this produces highly consistent 
trends, with a correlation of 0.981 with the baseline results.

However, given the high correlation between executive constraints and polity2, we also access the Freedom House index of civil liberties (introduced by Gastil et al., 1991) as another proxy for the quality of political institutions (Scully, 1988; Winiecki, 2004; Mirestean and Tsangarides, 2016). With an extensive sample of 151 countries (95 percent of the world population) over 1983 to 2012, the Ginis adjusted for civil liberties also highlight a general downward trend in the contribution of institutions from the late 1980s, as visualized in Panel $B$.

Next, considering that all results so far rely on latitude, landlocked, and island to proxy for geographical differences, we draw alternative geography proxies from Gallup et al. (2010), given their use in the associated literature (Gallup et al., 1999; Mirestean and Tsangarides, 2016). Following Gallup et al. (1999), this set of variables consists of $(i)$ the share of land in tropical conditions, $(i i)$ the mean distance to the nearest seanavigable river or coastline, (iii) the share of land area within 100 kilometers of ice-free coast, $\mathrm{t}(i v)$ the ratio of population within 100 kilometers of navigable river or ice-free coast to the total population, and $(v)$ the distance from centroid of country to the nearest sea-navigable river or coast (in kilometers). These variables are summarized in Table A.2 of the appendix. Panel $C$ confirms that the key finding prevails when using these alternative variables for geography.

Consistent results also prevail when the non-responsibility set is composed solely of latitude or, alternatively, when using a set of regional dummies to control for countries' geography (Panels $D$ and $E$ ). Thus, the decreasing explanatory power of political institutions cannot be explained by differences in the physical environment of countries or by region-specific dynamics. Further, we source GDP per capita (PPP, 2005 constant prices) data from the Penn World Table (Heston et al., 2012) and confirm that the baseline results are not sensitive to measuring income inequality using an alternative round of ICP PPP estimates (Panel $F$ ).

Until now, we have weighted each country equally to calculate Ginis which measure un- 
Panel A: 92 countries; $1980-2012$;
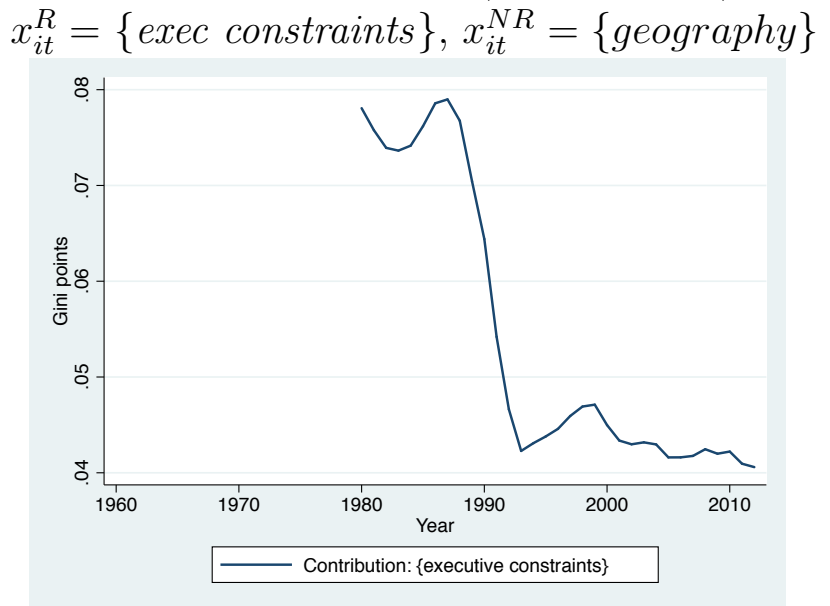

Panel C: 94 countries; 1960 - 2012;

$x_{i t}^{R}=\{$ polity2 $\} ; x_{i t}^{N R}=\{$ alternative geography $\}$

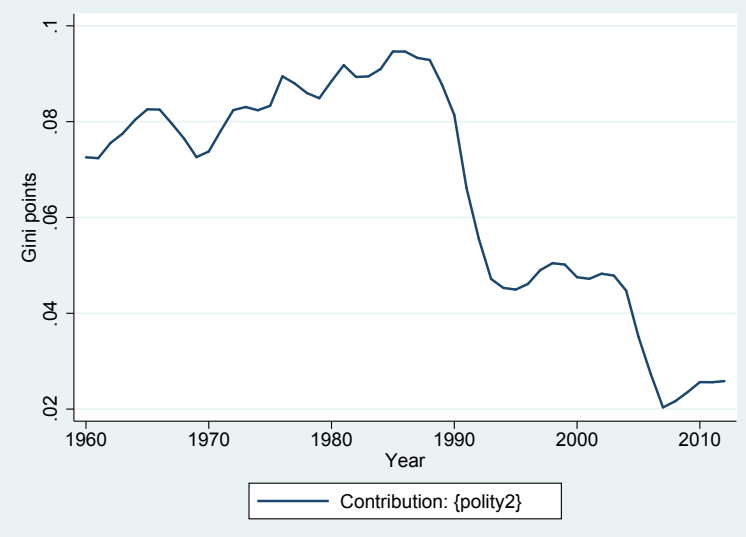

Panel E: 94 countries; 1960 - 2012; $x_{i t}^{R}=\{$ polity 2$\}, x_{i t}^{N R}=\{$ regions $\}$

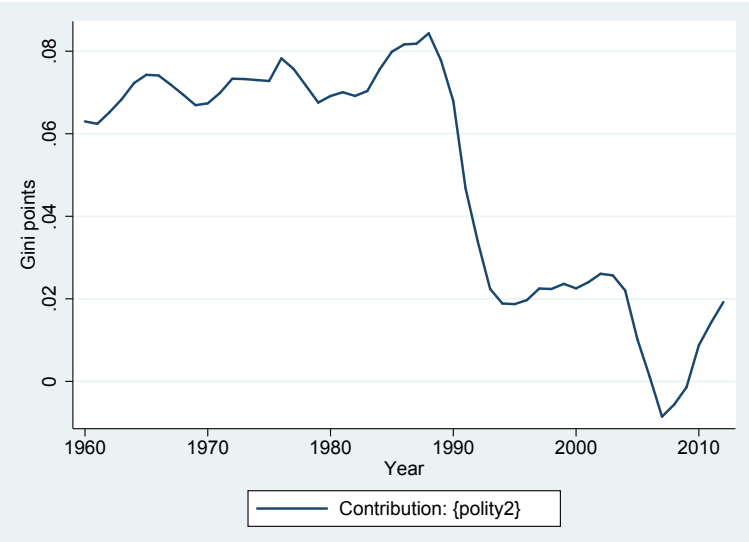

Panel B: 151 countries; 1983 - 2012; $x_{i t}^{R}=\{$ civil liberties $\}, x_{i t}^{N R}=\{$ geography $\}$

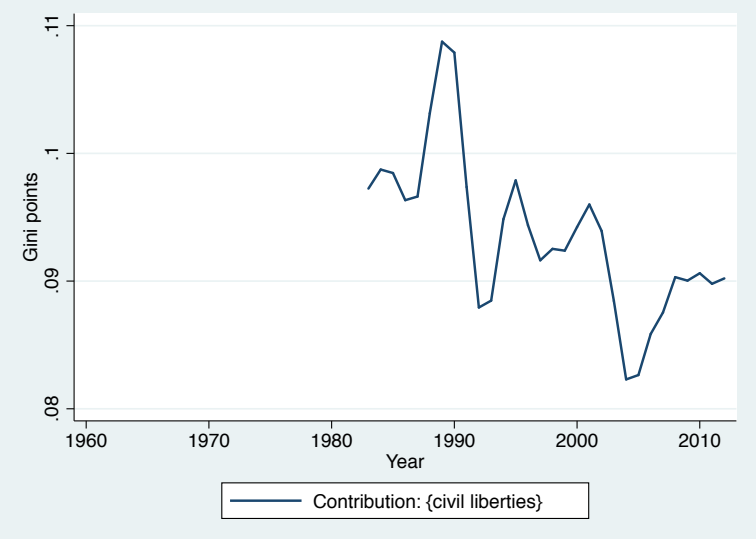

Panel D: 95 countries; 1960 - 2012; $x_{i t}^{R}=\{$ polity2 $\}$ and $x_{i t}^{N R}=\{$ latitude $\}$

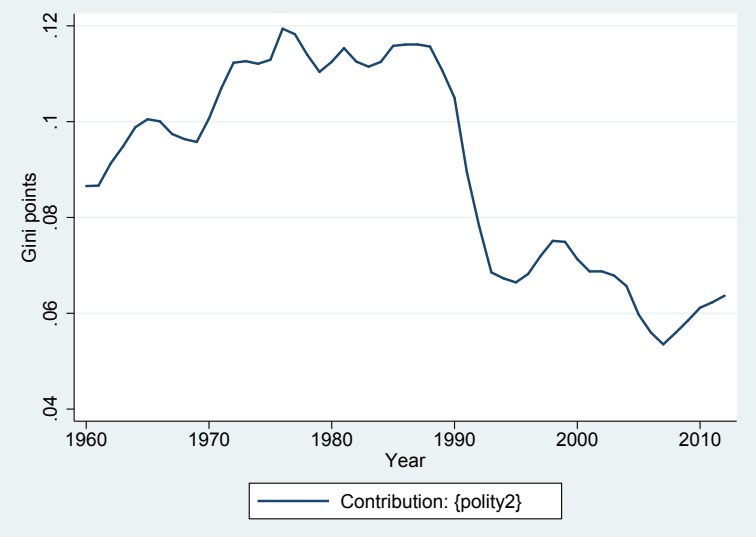

Panel F: 77 countries; 1960 - 2010; $x_{i t}^{R}=\{$ polity 2$\}, x_{i t}^{N R}=\{$ geography $\}$; $y_{i t}=\{G D P$ per capita $(P W T)\}$

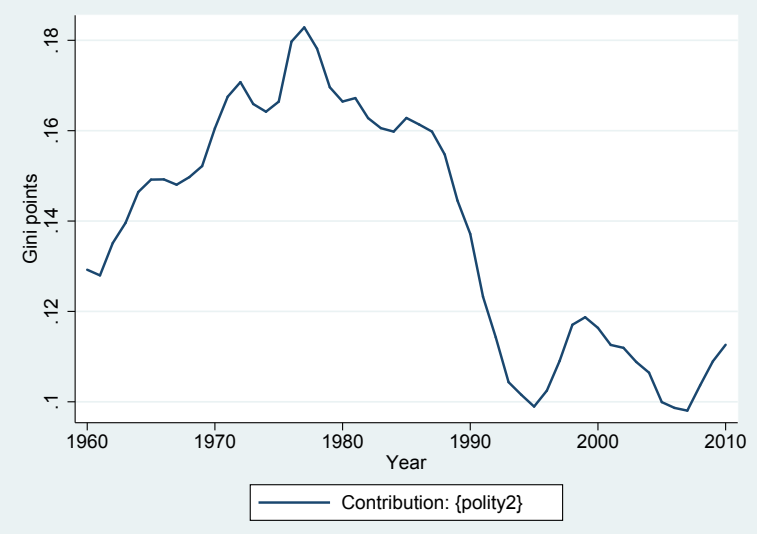

Figure 6: Explanatory power of institutional quality (polity2) for international inequality across various robustness checks. 
weighted international inequality. Alternatively, if one is concerned with the distribution of income among all individuals in the world (global inequality), weighting countries by the size of their population moves one step in this direction. Therefore, we also estimate population-weighted standard and adjusted Ginis by expanding the data in proportion to each country's share of total world population in any given year (Figure 7, Panel $A$ ).

Panel A: Gini coefficients

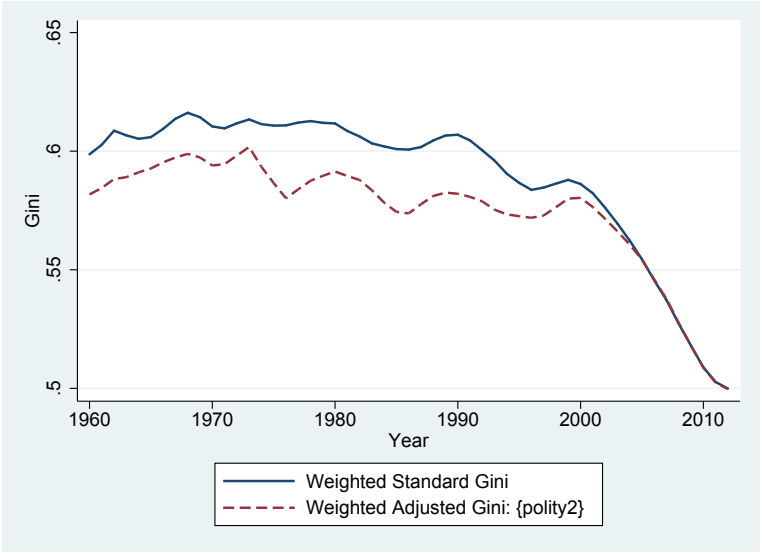

Panel B: Explanatory power

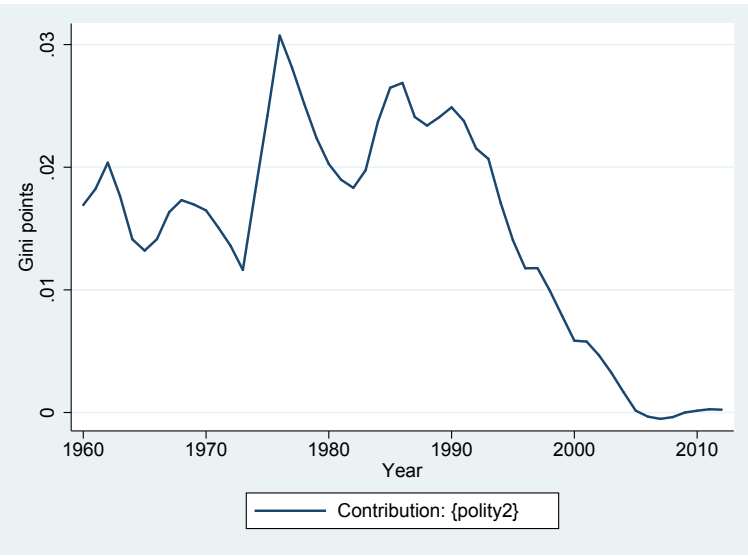

Figure 7: Considering population-weighted inequality, displaying annual Ginis for the baseline sample of 95 countries from 1960 to 2012, where $x_{i t}^{R}=\{$ polity2 $\}$ and $x_{i t}^{N R}=\{$ geography $\}$.

Here, China matters far more than Luxembourg. In line with rapid growth in China, as well as India, the standard Gini fell quickly from 1990. ${ }^{21}$ Assessing the contribution of political institutions to this population-weighted inequality by taking differences between the standard and adjusted Ginis, we find that the explanatory power of institutions still declines substantially over the last two decades (Figure 7, panel $B$ ). Regardless of whether we are concerned with weighted or unweighted inequality, results suggest that over 20 years ago institutional quality was substantially more important for explaining inequality than it is today.

\footnotetext{
${ }^{21}$ Figure A.1 in the appendix highlights the importance of China in driving this downward trend in population-weighted international inequality.
} 


\subsection{Considering Cultural Attributes and Education}

In order to ensure that the baseline estimates are indeed reflecting changes in the explanatory power of political institutions, we next control for cultural attributes and education as the remaining fundamental determinants of income levels. We test several alternative proxies for culture and education and consider all of the alternative orders in which culture, education, and institutions might be included in the responsibility set. ${ }^{22}$

\subsubsection{The Role of Culture}

Following Acemoglu et al. (2005), we begin by considering culture as a third fundamental determinant, in addition to institutions and geography. Given that a range of cultural attributes have been identified as important for countries' economic development (see appendix section A.3.2 for more detail), we use alternative sets of variables to capture a variety of cultural differences across countries. For each of these sets of variables, we first derive adjusted Gini 1 (AG 1), which is adjusted for institutional differences only, i.e., with cultural attributes and geography remaining in the non-responsibility set. Then, AG 2 is computed, which simultaneously adjusts for both countries' institutional and cultural differences, with only geography remaining in the non-responsibility set.

As a first proxy for countries' culture we employ four cultural traits variables, which are drawn from the World Values Survey (1981) (WVS) and have been found to be significant for countries' income levels (Guiso et al., 2004, 2006; Tabellini, 2010). These variables capture the extent of 'social capital' (trust and respect) and 'confidence in the individual' (obedience and control). ${ }^{23}$ As the WVS does not provide a balanced panel of data, we

\footnotetext{
${ }^{22}$ It is worth briefly mentioning the potential role that international trade (or integration) might play as a 'deep' determinant of income levels (Dollar and Kraay, 2004; Rodrik et al., 2004). In keeping with Acemoglu (2008) who view trade as a more proximate factor (where incentives for trade are ultimately shaped by the laws and regulations, i.e., institutions of society), we do not consider trade as a major fundamental determinant. Indeed, Rodrik et al. (2004) note that 'one can question whether it is appropriate to treat trade as one of the ultimate determinants of economic prosperity'. Regardless, the downward trend in the explanatory power of institutions is still apparent when we control for countries' level of integration using trade to GDP ratios (drawn from The World Bank, 2016; see Figure A.2 in the appendix) or the KOF index of economic globalization (Dreher, 2006; see Figure A.3).

${ }^{23}$ Each of these cultural traits is categorical and reflects the answers of a representative sample of
} 
use the available individual-level responses across all years to generate average measures of these cultural traits for each country. Therefore, and because of data availability, these trait variables are assumed to be time-invariant, which is consistent with the notion that many cultural aspects often tend to change slowly over time, if at all (Roland, 2004). Using these four cultural traits restricts the sample to 55 countries, which still represents a significant share of the world population with 79 percent.

Figure 8 presents the corresponding standard Ginis and both AGs 1 and 2, as well as the contribution of each set of variables to inequality. Most importantly, the downward trend in the contribution of institutions from the late 1980s still remains. Also, from the late 1980s onwards, the explanatory power of institutions and culture appear to diverge. While institutions are clearly explaining less, these results suggest that cultural differences might have become more important for explaining international inequality over the last two decades. We find similar trends when considering a larger sample of 67 countries (from 1980) (Figure A.4 in the appendix), as well as when Ginis are derived by adjusting for cultural attributes first, then followed by institutional quality (Figure A.5).

Panel A: Gini coefficients

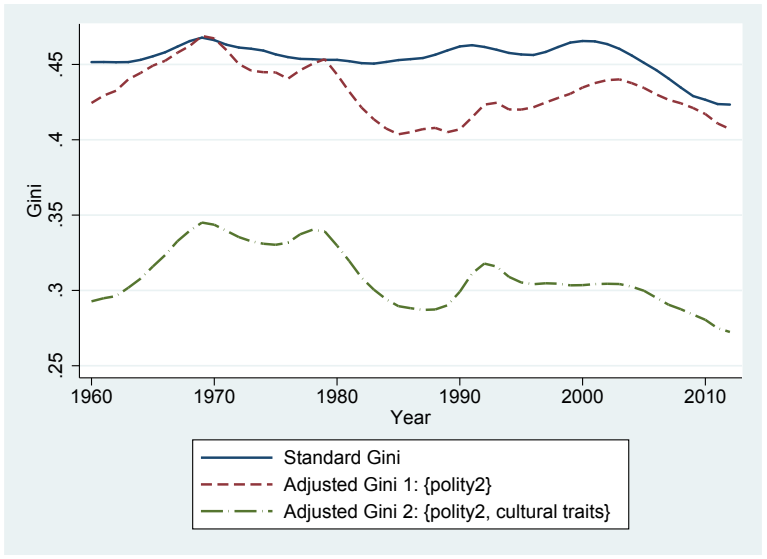

Panel B: Explanatory power

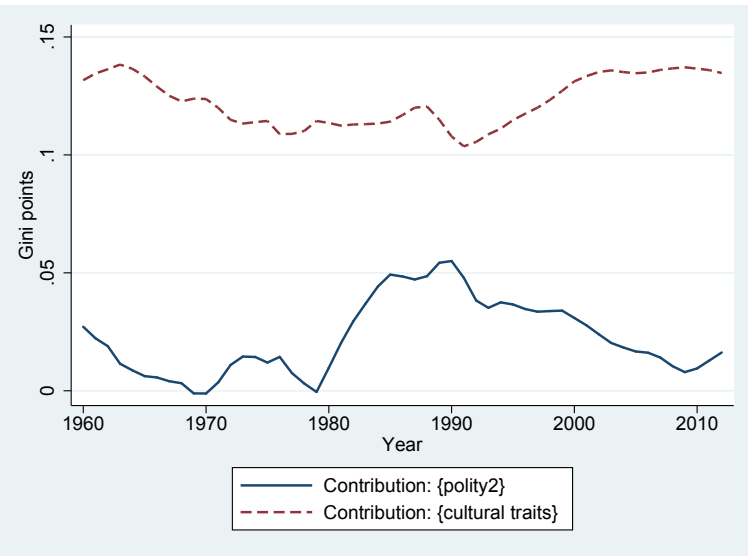

Figure 8: Annual Ginis for 55 countries from 1960 to 2012, where AG 1: $x_{i t}^{R}=\{$ polity2 $\}$ and $x_{i t}^{N R}=\left\{\right.$ cultural traits, geography\}; AG 2: $x_{i t}^{R}=\{$ polity2, cultural traits $\}$ and $x_{i t}^{N R}=\{$ geography $\}$.

individuals from each country. For example, trust records responses to the question 'Generally speaking, would you say that most people can be trusted or that you can't be too careful in dealing with people?' (World Values Survey, 1981). WVS data has been reported in six waves, with the first from 1981 to 1984. 
As a second proxy for culture, we draw on Hofstede et al.'s (2010) cultural dimensions. We employ two specifications, including all six dimensions (individualism, indulgence, long term orientation, masculinity, power distance, and uncertainty avoidance), as well as individualism by itself, given its particular significance for economic development (Gorodnichenko and Roland, 2011) ${ }^{24}$ Across both tests, the downward trend in the explanatory power of institutions persists (Figures A.6 and Figure A.7).

Lastly, we use the shares of major religions in each country as an alternative, timevariant proxy for national culture (e.g., see Guiso et al., 2003, for the importance of religion in economic development). We access data from the World Religion Dataset (Maoz and Henderson, 2013) to form variables for the percentage of each country's population adhering to Buddhism, Catholicism, Islam, Judaism, Protestantism, or other minor denominations. As data are only available every half-decade, results are restricted to 11 observations over the period of 1960 to 2010 . However, the contribution of institutions still falls substantially from the late 1980s onwards (Figure A.8).

\subsubsection{The Role of Education}

We next control for cross-country differences in education, accessing data from Barro and Lee (2013). Here, we consider education in line with Glaeser et al. (2004), who attest to the primacy of human capital as a basic source of economic growth (consistent with the arguments of Barro, 1999, and Przeworski, 2000). Initially, we employ a measure of secondary education attainment. Moving the secondary education variable into the responsibility set allows us to derive AG 3, which estimates the inequality between countries that cannot be explained by differences in political institutions, culture, or education.

Data availability from Barro and Lee (2013) allows us to compute Ginis for a sample of 53 countries ( 75 percent of the world population), for every fifth year over 1960 to

\footnotetext{
${ }^{24}$ For example, individualism measures a country's preference for a 'loosely-knit social framework' as a score out of 100 (Hofstede et al., 2010). Countries that score highly in terms of individualism tend to value personal freedom and achievement more than the interests of the group, i.e., collectivism (Gorodnichenko and Roland, 2011).
} 
2010. The corresponding results are displayed in Figure 9 and, as before, the key result prevails. Panel $B$ plots the respective contributions of each determinant. The addition of education to the responsibility set has no impact on our adjusted inequality measure from 1980 onward (and actually serves to increase the adjusted Gini prior to that time).

Panel A:: Gini coefficients

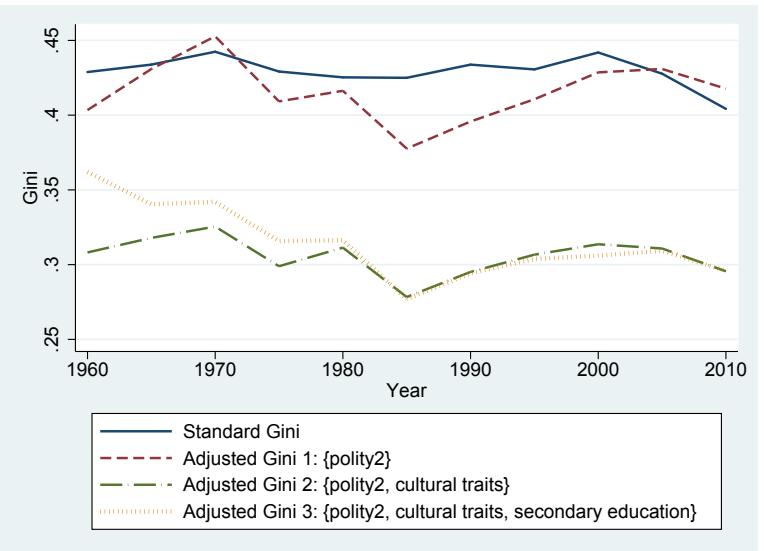

Panel B: Explanatory power

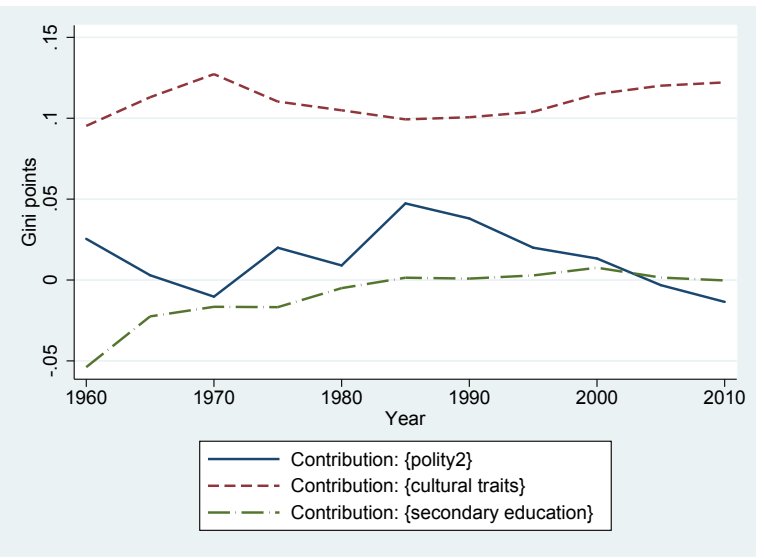

Figure 9: Ginis every five years for 53 countries (75\% of world population) from 1960 to 2010, where AG 1: $x_{i t}^{R}=\{$ polity2 $\}$ and $x_{i t}^{N R}=\{$ cultural traits, secondary education, geography\}; $\mathrm{AG} 2: x_{i t}^{R}=\{$ polity2, cultural traits $\}$ and $x_{i t}^{N R}=$ $\{$ secondary education, geography $\} ; \mathrm{AG} 3: x_{i t}^{R}=\{$ polity2, cultural traits, secondary education $\}$ and $x_{i t}^{N R}=\{$ geography $\}$.

Additionally, the downward trend in the explanatory power of institutions is apparent when using the average number of school years, primary educational attainment, or tertiary educational attainment as alternative indicators (Figure A.9).

The apparent contribution of each determinant may also vary, depending on the order in which determinants are moved into the responsibility set. Consequently, we derive results for all five alternative arrangements of the proxies for political institutions, culture, and education. Figure A.10 shows that regardless of the order of inclusion, differences in institutional quality consistently explain less of inequality today, compared to two decades ago.

The results from this expanded specification imply that unfair inequality has in fact stayed relatively constant or even slightly decreased since the late 1980s (Figure 9). This 
contrasts the case where countries are held responsible only for the quality of their political institutions and unfair inequality can be said to have substantially increased. Therefore, whether inequality between countries has become more or less fair over the last 20 years critically depends on one's views as to which (if any) fundamental determinants countries should be held responsible for. Irrespective of these views, however, one trend that is clear is that over the last two decades, differences in political institutions have been able to explain less and less of international inequality.

\section{Regional Explanations}

To test whether major regional events are able to explain this decline in the importance of political institutions for international inequality, we consider three main developments over the late 1980s and early 1990s: the fall of the Soviet Union, the rise of China and other Asian success stories, and institutional monocropping in Africa.

\subsection{The Fall of the Soviet Union}

First, we turn to the fall of the Iron Curtain. Given that a 'significant acceleration of the convergence process [in institutional quality] resulted from the end of the Cold War' (Savoia and Sen, 2016), one might speculate that the rapid drop in the explanatory power of institutions over 1988 to 1993 could be due to the coincident transitions in a number of Eastern European countries. To test this explanation, we remove Eastern Europe from the baseline sample, forming a new sub-sample of 89 countries.

Panel $A$ in Figure 10 compares the results from this sub-sample with the baseline results for all 95 countries. If changes in Eastern Europe were driving the decreased explanatory power of institutions, one would expect the rapid drop to disappear in the new results. However, this is not the case. The contribution of institutions in fact falls by even more when Eastern European countries are not in the sample. Thus, the declining importance of institutions for inequality is not simply a result of institutional 
improvements in Eastern Europe following the collapse of the Soviet Union.

\subsection{The Rise of China and Asian Growth}

A second potential explanation focuses on the rise of China and a number of other Asian success stories that enjoyed high growth rates prior to and around the 1990s. Indeed, the extraordinary rise of China has provided one force for economic convergence between countries. And yet, by conventional measures, China has maintained relatively low quality political institutions over this period (Rodrik, 2003). Thus, it is possible that the inability of political institutions to explain Chinese growth could drive our benchmark finding.

Although we have already considered population-weighted inequality in Figure 7 to account for the importance of China, panel $B$ of Figure 10 excludes all Asian countries from our sample. But, here again, the drop in the explanatory power of political institutions prevails, as highlighted in the right graph of panel $B$. Although the drop decreases marginally in terms of its magnitude, we still observe the same tendency, especially when considering the period following the 1990s - political institutions continue to explain less of international inequality and Asia does not seem to be the unique driver for this development.

\subsection{Institutional Monocropping in Africa}

A final possible explanation considers 'institutional monocropping', a term coined by Evans (2004) to refer to the imposition of uniform institutional blueprints upon the global South. As this concept may be less popular than our first two explanations, we briefly provide a historical background. In line with a number of 'best practice' reforms prescribed by the Washington Consensus (Dunning and Pop-Eleches, 2004), the 1990s saw particularly rapid transplantation of what were presumed 'ideal' Anglo-American institutions onto many developing economies (Evans, 2004; Savoia and Sen, 2016). However, this institutional monocropping often did not result in the expected improvements to economic performance (Evans, 2004; Chang, 2007). While monocropping saw institutional quality 
Panel $A$ : Excluding Eastern Europe
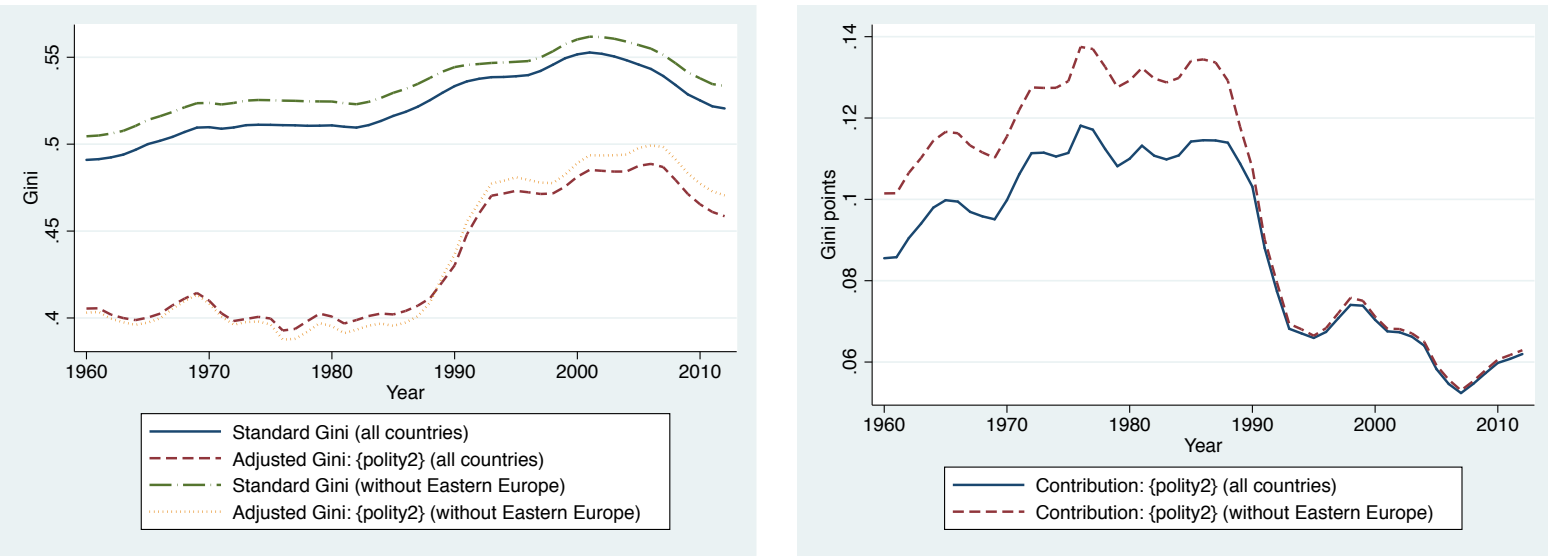

Panel B: Excluding Asia
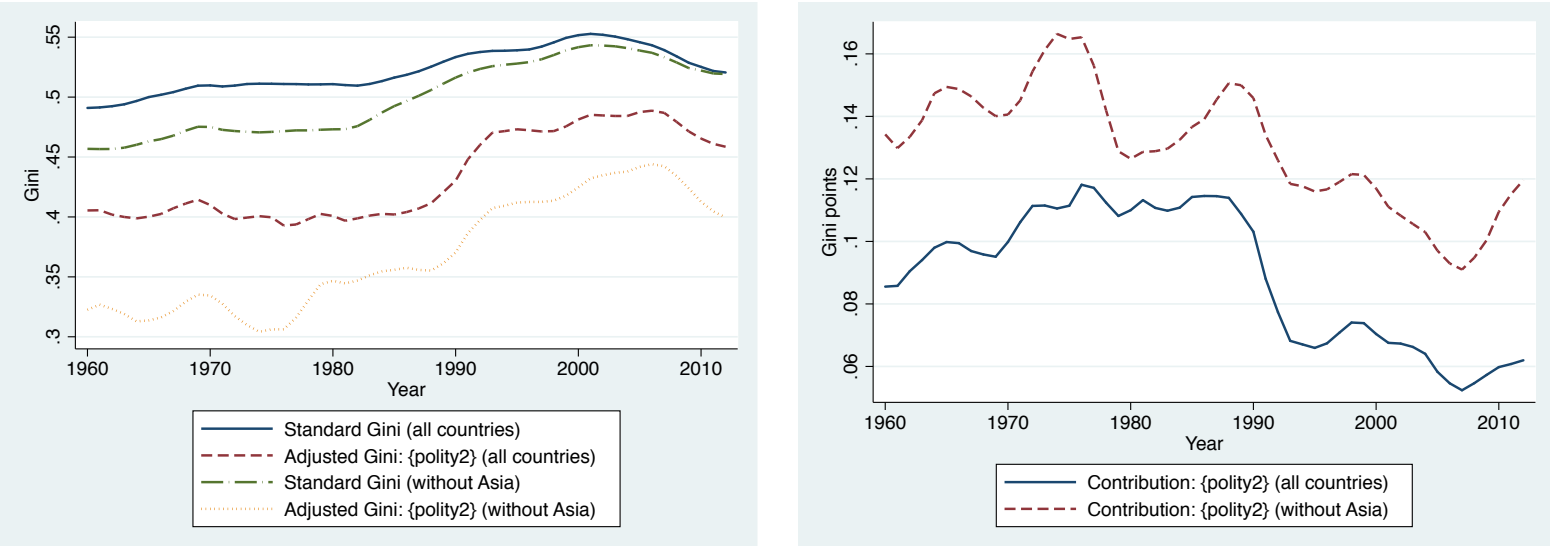

Panel $C$ : Excluding Africa
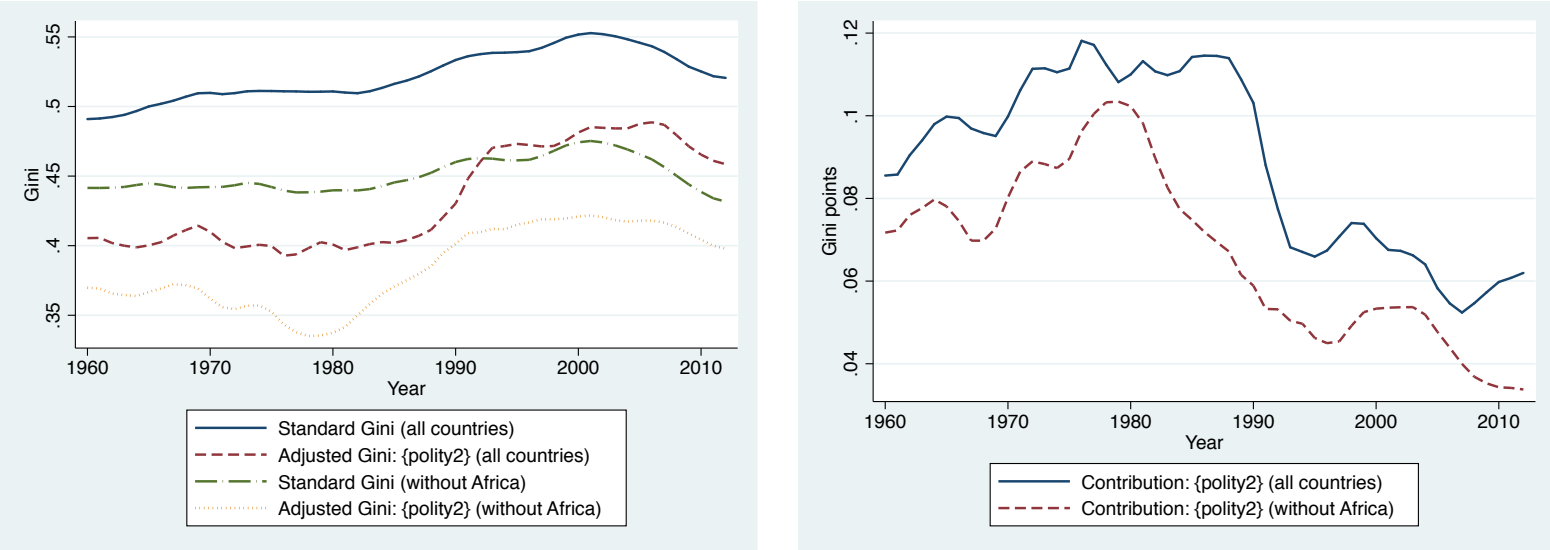

Figure 10: Excluding particular regions, showing the adjusted Gini (left) and the corresponding explanatory power of polity2 (right), where $x_{i t}^{R}=\{$ polity 2$\}$ and $x_{i t}^{N R}=\{$ geography $\}$. 
quickly 'improve', it did not generate matching changes to countries' income levels. In this way, monocropping might be one factor leading to the decreasing explanatory power of institutions for international inequality.

This monocropping explanation appears even more convincing once we consider why it produced such disappointing results. One explanation for the poor economic returns is that there was ineffective enforcement of the correct functioning of the imposed institutions on behalf of the government (Khan, 2012). This would suggest a disparity between 'official' measures and the actual quality of institutions in these countries, which might explain the decreasing explanatory power of institutions. However, a more widely supported explanation is that the cultural and social context of the recipient countries was typically not accounted for and was not conducive to the success of the imposed institutions (Djankov et al., 2003; Roland, 2004; Rodrik, 2008). Zweynert and Goldschmidt (2006) explain that 'if formal institutions are transferred from one country to another, they mingle with the 'soil' of the prevailing informal constraints of behavior' and Acemoglu et al. (2005) acknowledge that, to some extent, culture may influence the outcomes of a set of institutions. Thus, the blueprint reforms may have underestimated the importance of local knowledge and 'supporting norms' for building successful institutions (Rodrik et al., 2004; Rodrik, 2006). For example, regarding monocropping in Africa, Mkandawire (2012) contends that the 'practice has blunted the effectiveness of institutions by denying them context specificity.' Dunning and Pop-Eleches (2004) cite Botswana, China, and Mauritius as contrasting examples, which illustrate the importance of context-specific institutions, as opposed to 'universal recipes' for success.

Given evidence of rapid institutional monocropping in Africa around the early 1990s (Mkandawire, 2012) and the methodological difficulty of listing exactly those countries in which institutional monocropping was particularly enforced, we focus on Africa. Panel $C$ of Figure 10 presents results when excluding Africa from our global sample. However, overall, we continue to observe the continuous downward trend in the role of political institutions. In fact, once African countries are excluded from the sample, this develop- 
ment sets in even earlier around the early 1980s, as can be seen in the right graph of panel $C$. Thus, if anything, Africa appears to have delayed the declining role of political institutions in explaining international inequality for a few years.

Overall, these three major global events - the fall of the Soviet Union, the rise of Asia, and institutional monocropping - appear unlikely as the sole driver of the declining importance of political institutions to explain international inequality.

\section{Conclusion}

This paper examines the role of political institutions as a major fundamental determinant of income inequality between countries. If we are concerned with the question of whether developments in international inequality are man-made, then distinguishing between the role of 'humanly-devised' political institutions and exogenous geographical conditions can provide us with a much more detailed picture than analyzing standard Gini indices or other basic measures of income inequality.

First, we derive adjusted Gini coefficients, which capture the portion of inequality that cannot be attributed to differences in political institutions. We find that since the late 1980s it has become increasingly difficult to explain inequality between countries with political institutions. 20 years ago, institutions could explain almost double the portion of inequality than they can today, according to baseline estimates analyzing 95 countries (equivalent to 85 percent of the world population). Although international inequality has been decreasing over the new millennium, this does not seem to be explained well by differences in institutional quality. This result remains robust when using a larger sample of countries (over a shorter timeframe), considering alternative variables, assessing population-weighted inequality, and incorporating other major fundamental determinants of income (culture, education, and geography). In turn, the explanatory power of geography - a fundamental determinant of income levels that is arguably not within the realm of human influence - has doubled since the 1980s. 
We then consider three major historical developments to assess whether this phenomenon is indeed global or driven by a particular region: the fall of the Soviet Union, the rise of China and other Asian success stories, and institutional monocropping. However, neither excluding Eastern Europe, nor Asia or Africa, produces qualitatively different insights, indicating that the decline in the explanatory power of political institutions for international inequality since the late 1980s is indeed a global phenomenon.

Naturally, our study seeks to explain large fundamental developments by using aggregated country-level data and one can find several concerns, as well as avenues for promising future research. We wish to briefly mention two of these. First, inequality between countries is only one (albeit large) component of global inequality and future studies may seek to incorporate data regarding within-country inequality in order to provide a more complete picture. Second, we focus on the fundamental determinants of income levels and, thus, exploring the role of the so-called proximate determinants (e.g., factor accumulation and productivity) in explaining international inequality might produce more detailed insights. For these and other reasons, we remain humble in the interpretation of our findings.

Nevertheless, the consistency with which our findings emerge throughout numerous different specifications is startling, indicating a global development. In general, if we seek to decrease inequality, of primary interest are likely those drivers that $(i)$ have been proven to matter and $(i i)$ might be changed over time. 'Humanly-devised' political institutions (North, 1990) constitute one major fundamental determinant that seems to fit this bill. Our results imply that inequality across countries has become considerably less fair, i.e., less explainable by political institutions, since the late 1980s. 


\section{References}

Acemoglu, D. (2008). Introduction to Modern Economic Growth. Princeton University Press.

Acemoglu, D. and Johnson, S. (2005). Unbundling Institutions. Journal of Political Economy, 113(5):949-995.

Acemoglu, D., Johnson, S., and Robinson, J. A. (2001). The Colonial Origins of Comparative Development: An Empirical Investigation. American Economic Review, 91(5):1369-1401.

Acemoglu, D., Johnson, S., and Robinson, J. A. (2002). Reversal of fortune: Geography and institutions in the making of the modern world income distribution. The Quarterly Journal of Economics, 117(4):1231-1294.

Acemoglu, D., Johnson, S., and Robinson, J. A. (2005). Institutions as a fundamental cause of long-run growth. Handbook of Economic Growth, 1:385-472.

Acemoglu, D. and Robinson, J. (2012). Why Nations Fail: The Origins of Power, Prosperity, and Poverty. Crown Business.

Alesina, A., Giuliano, P., and Nunn, N. (2013). On the Origins of Gender Roles: Women and the Plough. The Quarterly Journal of Economics, 128(2):469-530.

Almås, I., Cappelen, A. W., Lind, J. T., Sørensen, E. Ø., and Tungodden, B. (2011). Measuring unfair (in)equality. Journal of Public Economics, 95(7):488-499.

Almås, I., Havnes, T., and Mogstad, M. (2012). Adjusting for age effects in cross-sectional distributions. The Stata Journal, 12(3):393-405.

Anand, S. and Segal, P. (2008). What do we know about global income inequality? Journal of Economic Literature, 46(1):57-94. 
Anand, S. and Segal, P. (2014). The global distribution of income. In Atkinson, A. B. and Bourguignon, F., editors, Handbook of Income Distribution, volume 2A. Elsevier.

Aristizábal-Ramírez, M., Canavire Bacarreza, G. J., and Jetter, M. (2015). Income Inequality in Bolivia, Colombia, and Ecuador: Different Reasons. IZA Discussion Paper No. 9210 .

Barro, R. J. (1999). Determinants of democracy. Journal of Political Economy, 107(6):158-183.

Barro, R. J. and Lee, J. W. (2013). A new data set of educational attainment in the world, 1950-2010. Journal of Development Economics, 104:184-198.

Bossert, W. (1995). Redistribution mechanisms based on individual characteristics. Mathematical Social Sciences, 29(1):1-17.

Bourguignon, F., Levin, V., and Rosenblatt, D. (2004). Declining international inequality and economic divergence: Reviewing the evidence through different lenses. Economie internationale, 4(100):13-26.

Brock, W. A. and Durlauf, S. N. (2001). What have we learned from a decade of empirical research on growth? Growth empirics and reality. The World Bank Economic Review, $15(2): 229-272$.

Carpantier, J.-F. and Sapata, C. (2013). An ex-post view of inequality of opportunity in France and its regions. Journal of Labor Research, 34(3):281-311.

Chang, H.-J. (2007). Understanding the relationship between institutions and economic development - some key theoretical issues. In Chang, H.-J., editor, Institutional Change and Economic Development. Citeseer.

Chong, A. and Gradstein, M. (2007). Inequality and institutions. The Review of Economics and Statistics, 89(3):454-465. 
Chotikapanich, D., Griffiths, W. E., Prasada Rao, D., and Valencia, V. (2012). Global income distributions and inequality, 1993 and 2000: Incorporating country-level inequality modeled with beta distributions. Review of Economics and Statistics, 94(1):52-73.

Deaton, A. and Aten, B. (2014). Trying to understand the PPPs in ICP 2011: Why are the results so different? Working Paper No. 20244, National Bureau of Economic Research.

Djankov, S., Glaeser, E., La Porta, R., Lopez-de Silanes, F., and Shleifer, A. (2003). The new comparative economics. Journal of Comparative Economics, 31(4):595-619.

Dollar, D. and Kraay, A. (2004). Trade, growth, and poverty. The Economic Journal, 114(493):22-49.

Dowrick, S. and Akmal, M. (2005). Contradictory trends in global income inequality: A tale of two biases. Review of Income and Wealth, 51(2):201-229.

Dreher, A. (2006). Does globalization affect growth? Evidence from a new index of globalization. Applied Economics, 38(10):1091-1110.

Dunning, T. and Pop-Eleches, G. (2004). From transplants to hybrids: Exploring institutional pathways to growth. Studies in Comparative International Development, $38(4): 3-29$.

Durlauf, S. N., Johnson, P. A., and Temple, J. R. (2005). Growth econometrics. Handbook of Economic Growth, 1:555-677.

Evans, P. (2004). Development as institutional change: The pitfalls of monocropping and the potentials of deliberation. Studies in Comparative International Development, $38(4): 30-52$.

Figueiredo, E. and Junior, J. L. d. S. N. (2014). More equal but not so fair: An analysis of Brazilian income distribution from 1995 to 2009. Empirical Economics, 46(4):13251337. 
Firebaugh, G. (1999). Empirics of world income inequality. American Journal of Sociology, 104(6):1597-1630.

Firebaugh, G. and Goesling, B. (2004). Accounting for the recent decline in global income inequality. American Journal of Sociology, 110(2):283-312.

Gallup, J. L., Mellinger, A. D., and Sachs, J. D. (2010). Geography datasets. Harvard Centre for International Development Dataverse.

Gallup, J. L., Sachs, J. D., and Mellinger, A. D. (1999). Geography and economic development. International Regional Science Review, 22(2):179-232.

Gapminder (2014). Gross Domestic Product per capita by Purchasing Power Parities Version 15. Retrieved from //www.gapminder.org/data. Data compiled from several sources by Mattias Lindgren.

Gastil, R. D. et al. (1991). Freedom in the world: Political rights and civil liberties. Freedom House.

Glaeser, E. L. (2008). Inequality. In Weingast, B. R. and Wittman, D., editors, The Oxford Handbook of Political Economy. Oxford University Press.

Glaeser, E. L., La Porta, R., Lopez-de Silanes, F., and Shleifer, A. (2004). Do institutions cause growth? Journal of Economic Growth, 9(3):271-303.

Gleditsch, K. S. and Ward, M. D. (1997). Double Take: A Re-examination of Democracy and Autocracy in Modern Polities. Journal of Conflict Resolution, 41(3):361-383.

Gorodnichenko, Y. and Roland, G. (2011). Which dimensions of culture matter for longrun growth? The American Economic Review, 101(3):492-498.

Guiso, L., Sapienza, P., and Zingales, L. (2003). People's opium? Religion and economic attitudes. Journal of Monetary Economics, 50(1):225-282. 
Guiso, L., Sapienza, P., and Zingales, L. (2004). The role of social capital in financial development. The American Economic Review, 94(3):526-556.

Guiso, L., Sapienza, P., and Zingales, L. (2006). Does culture affect economic outcomes? The Journal of Economic Perspectives, 20(2):23-48.

Hall, R. E. and Jones, C. I. (1999). Why do some countries produce so much more output per worker than others? The Quarterly Journal of Economics, 114(1):83-116.

Heston, A., Summers, R., and Aten, B. (2012). Penn World Table Version 7.1. Center of Comparisons of Production, Income and Prices at the University of Pennsylvania.

Hodler, R. and Raschky, P. A. (2014). Regional favoritism. The Quarterly Journal of Economics, 129(2):995-1033.

Hofstede, G., Hofstede, G. J., and Minkov, M. (2010). Cultures and Organizations: Software of the Mind. Revised and Expanded 3rd Edition. McGraw-Hill, New York, USA.

Hsieh, C.-T. and Klenow, P. J. (2010). Development accounting. American Economic Journal: Macroeconomics, 2(1):207-223.

Huang, Y. (2010). Political institutions and financial development: An empirical study. World Development, 38(12):1667-1677.

Hussey, A. and Jetter, M. (2016). Long term trends in fair and unfair inequality in the United States. Applied Economics, 29(1):1-17.

Inklaar, R. C., Rao, D. P., et al. (2014). Cross-country income levels over time: Did the developing world suddenly become much richer? Groningen Growth and Development Centre Research Memorandum No. 151. Forthcoming in American Economic Journal.

Johansson, K. and Lindgren, M. (2014). Documentation for life expectancy at birth (years) for countries and territories. The Gapminder Foundation, accessible via http : //www. gapminder. org, Gapminder Documentation 004. 
Keefer, P. and Knack, S. (1997). Why don't poor countries catch up? A cross-national test of an institutional explanation. Economic Inquiry, 35(3):590-602.

Khan, M. (2012). Governance and Growth: History, Ideology and Methods of Proof. In Noman, A., Botchwey, K., Stein, H., and Stiglitz, J. E., editors, Good Growth and Governance in Africa: Rethinking Development Strategies. Oxford University Press.

Knack, S. (1996). Institutions and the convergence hypothesis: The cross-national evidence. Public Choice, 87(3-4):207-228.

Knack, S. and Keefer, P. (1995). Institutions and economic performance: Cross-country tests using alternative institutional measures. Economics \& Politics, 7(3):207-227.

Konow, J. (1996). A positive theory of economic fairness. Journal of Economic Behavior $\&$ Organization, 31(1):13-35.

Lakner, C. and Milanovic, B. (2016). Global Income Distribution: From the Fall of the Berlin Wall to the Great Recession. The World Bank Economic Review, 30(2):203-232.

Lee, K. and Kim, B.-Y. (2009). Both institutions and policies matter but differently for different income groups of countries: Determinants of long-run economic growth revisited. World Development, 37(3):533 - 549 .

Lindgren, M. (2008). Documentation for GDP Per Capita by Purchasing Power Parities for countries and territories. The Gapminder Foundation.

Lindgren, M. (2011a). Documentation for GDP per capita by purchasing power parities for countries and territories. The Gapminder Foundation, accessible via http: // www. gapminder. org, Gapminder Documentation 001.

Lindgren, M. (2011b). Documentation for total population for countries and territories. The Gapminder Foundation, accessible via http: //www. gapminder. org, Gapminder Documentation 003. 
Maoz, Z. and Henderson, E. A. (2013). The world religion dataset, 1945-2010: Logic, estimates, and trends. International Interactions, 39(3):265-291.

Marshall, M. G., Gurr, T. R., and Jaggers, K. (2014). Dataset User's Manual: Polity IV Project. Center for Systemic Peace.

Marshall, M. G. and Jaggers, K. (2002). Polity IV Project: Political regime characteristics and transitions, 1800-2002.

Milanovic, B. (2005). Worlds Apart: Measuring International and Global Inequality. Princeton University Press.

Milanovic, B. (2012a). Global Inequality: From Class to Location, from Proletarians to Migrants. Global Policy, 3(2):125-134.

Milanovic, B. (2012b). Global inequality recalculated and updated: The effect of new PPP estimates on global inequality and 2005 estimates. The Journal of Economic Inequality, $10(1): 1-18$.

Milanovic, B. (2013). Global Income Inequality in Numbers: In History and Now. Global Policy, 4(2):198-208.

Mirestean, A. and Tsangarides, C. G. (2016). Growth determinants revisited using limited-information bayesian model averaging. Journal of Applied Econometrics, $31(1): 106-132$.

Mkandawire, T. (2012). Institutional Monocropping and Monotasking in Africa. In Noman, A., Botchwey, K., Stein, H., and Stiglitz, J. E., editors, Good Growth and Governance in Africa: Rethinking Development Strategies. Oxford University Press.

North, D. C. (1990). Institutions, Institutional Change and Economic Performance. Cambridge University Press. 
North, D. C. (1994). Economic performance through time. The American Economic Review, 84(3):359-368.

North, D. C. and Thomas, R. P. (1973). The Rise of the Western World: A New Economic History. Cambridge University Press.

Nunn, N. and Puga, D. (2012). Ruggedness: The blessing of bad geography in Africa. Review of Economics and Statistics, 94(1):20-36.

Nunn, N. and Wantchekon, L. (2011). The slave trade and the origins of mistrust in Africa. The American Economic Review, 101(7):3221-3252.

Ortiz, I. and Cummins, M. (2011). Global Inequality: Beyond the Bottom Billion - A Rapid Review of Income Distribution in 141 Countries. Working paper 1105, UNICEF, Division of Policy and Strategy.

Piketty, T., Goldhammer, A., and Ganser, L. (2014). Capital in the Twenty-First Century. Belknap Press of Harvard University Press Cambridge, MA.

Pritchett, L. (1997). Divergence, big time. The Journal of Economic Perspectives, 11(3):317.

Przeworski, A. (2000). Democracy and Development: Political Institutions and WellBeing in the World, 1950-1990, volume 3. Cambridge University Press.

Ram, R. (2015). International income inequality, 2005-2011: What a difference 6 years can make. Applied Economics, 47(56):6148-6154.

Ravallion, M. (2014). An Exploration of the International Comparison Program's New Global Economic Landscape. Working Paper No. 20338, National Bureau of Economic Research.

Rodrik, D. (2003). In Search of Prosperity: Analytic Narratives on Economic Growth. Princeton University Press. 
Rodrik, D. (2006). Institutions for high-quality growth: What they are and how to acquire them. In Roy, K. C. and Sideras, J., editors, Institutions, Globalisation and Empowerment. Edward Elgar Publishing.

Rodrik, D. (2008). Second-best institutions. American Economic Review, 98(2):100-104.

Rodrik, D., Subramanian, A., and Trebbi, F. (2004). Institutions rule: The primacy of institutions over geography and integration in economic development. Journal of Economic Growth, 9(2):131-165.

Roland, G. (2004). Understanding institutional change: Fast-moving and slow-moving institutions. Studies in Comparative International Development, 38(4):109-131.

Sachs, J. and Malaney, P. (2002). The economic and social burden of malaria. Nature, 415(6872):680-685.

Sachs, J. D. (2001). Tropical underdevelopment. Technical report, National Bureau of Economic Research.

Sachs, J. D. (2003). Institutions Don't Rule: Direct Effects of Geography on Per Capita Income. Working Paper No. 9490, National Bureau of Economic Research.

Sachs, J. D. and Warner, A. M. (1997). Fundamental sources of long-run growth. The American Economic Review, 87(2):184.

Sala-i-Martin, X. (1996). The classical approach to convergence analysis. The Economic Journal, 106(437):1019-1036.

Sala-i-Martin, X. (2006). The world distribution of income: Falling poverty and... convergence, period. The Quarterly Journal of Economics, 121(2):351-397.

Savoia, A., Easaw, J., and McKay, A. (2010). Inequality, democracy, and institutions: A critical review of recent research. World Development, 38(2):142-154. 
Savoia, A. and Sen, K. (2016). Do we see convergence in institutions? A cross-country analysis. The Journal of Development Studies, 52(2):166-185.

Scully, G. W. (1988). The institutional framework and economic development. Journal of Political Economy, 96(3):652-662.

Solt, F. (2016). The Standardized World Income Inequality Database. Social Science Quarterly.

Tabellini, G. (2010). Culture and institutions: Economic development in the regions of Europe. Journal of the European Economic Association, 8(4):677-716.

Tan, C. M. (2010). No one true path: Uncovering the interplay between geography, institutions, and fractionalization in economic development. Journal of Applied Econometrics, 25(7):1100-1127.

The World Bank (2016). World Development Indicators. Retrieved from http://www.databank.worldbank.org.

UN General Assembly (2015). Transforming our world: the 2030 agenda for sustainable development. New York: United Nations.

Voigtländer, N. and Voth, H.-J. (2012). Persecution Perpetuated: The Medieval Origins of Anti-Semitic Violence in Nazi Germany. Quarterly Journal of Economics, 127(3):13391392.

Winiecki, J. (2004). Determinants of catching up or falling behind: Interaction of formal and informal institutions. Post-Communist Economies, 16(2):137-152.

World Values Survey (1981). World Values Survey 1981-2014 Longitudinal Aggregate. World Values Survey Association. Retrieved from http://www.worldvaluessurvey.org.

Zweynert, J. and Goldschmidt, N. (2006). The two transitions in Central and Eastern Europe as processes of institutional transplantation. Journal of Economic Issues, 40(4):895-918. 